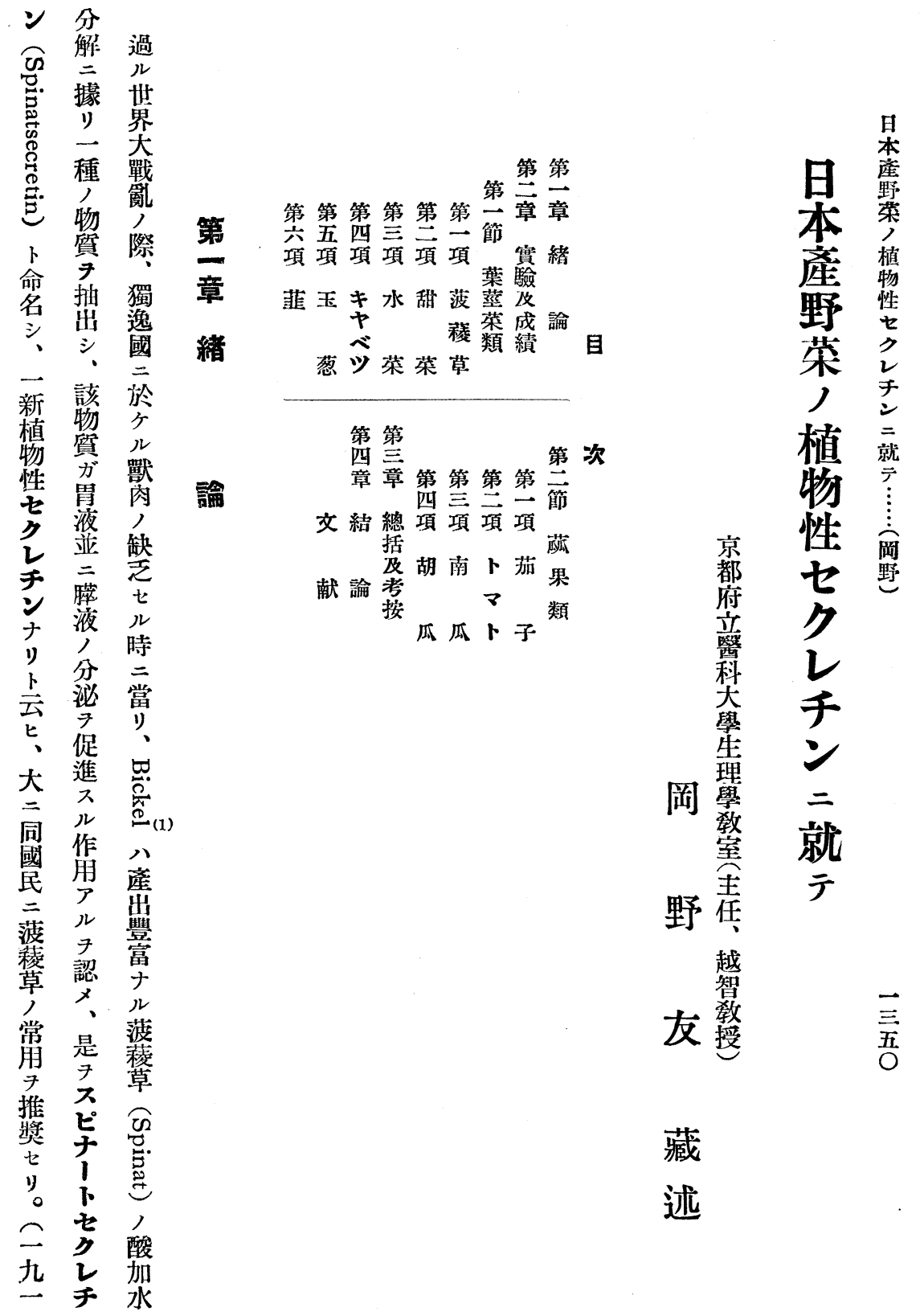




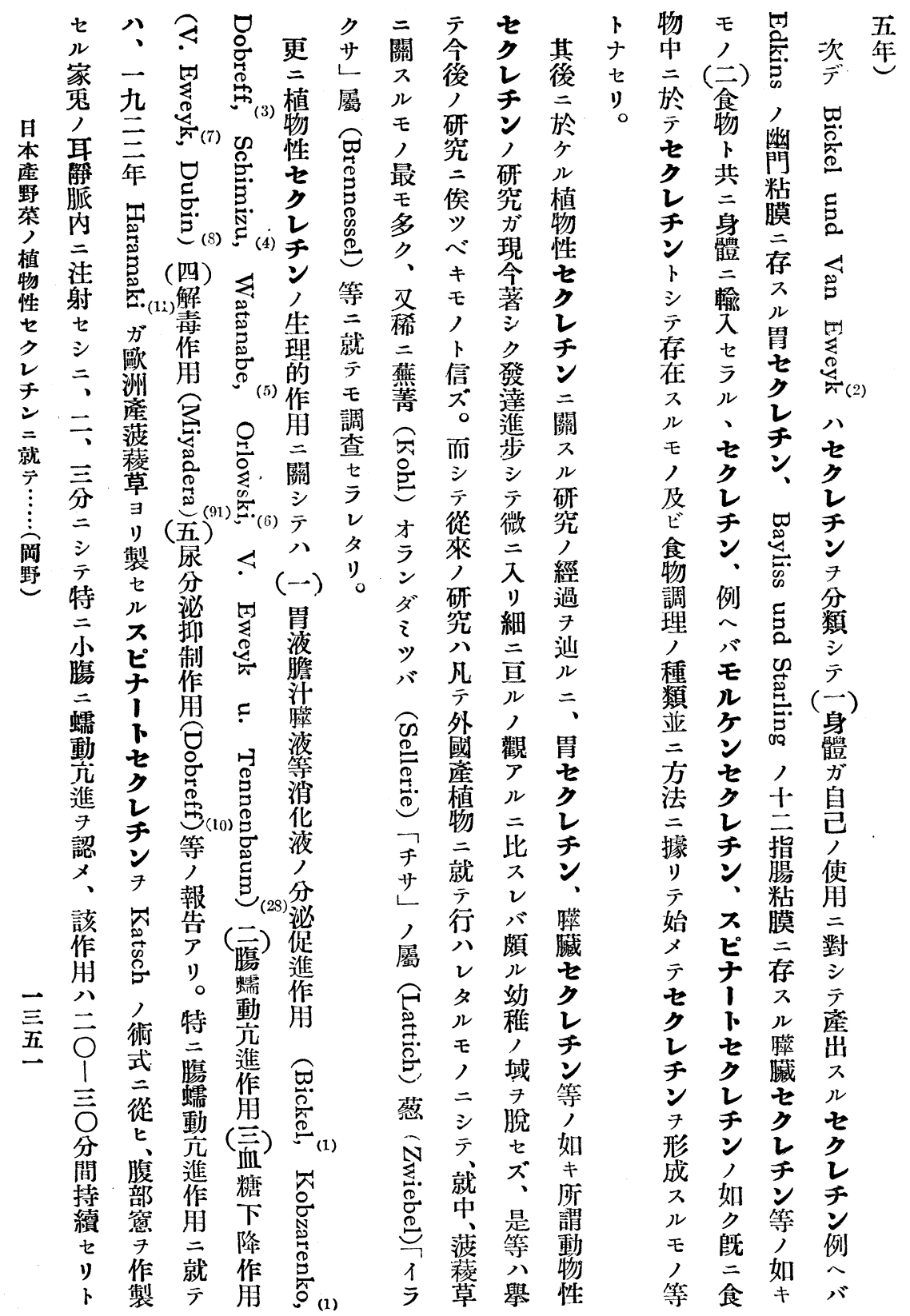




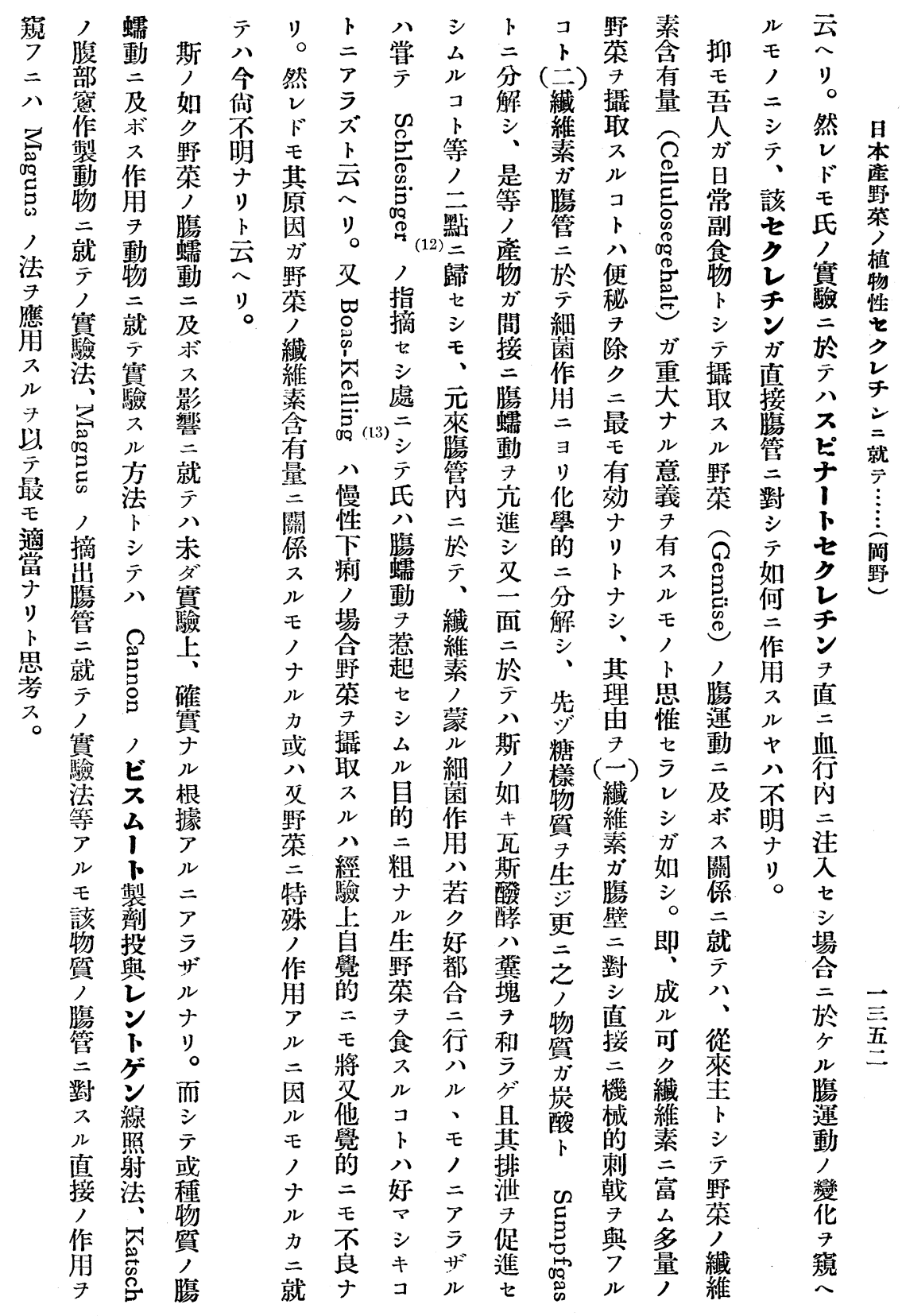




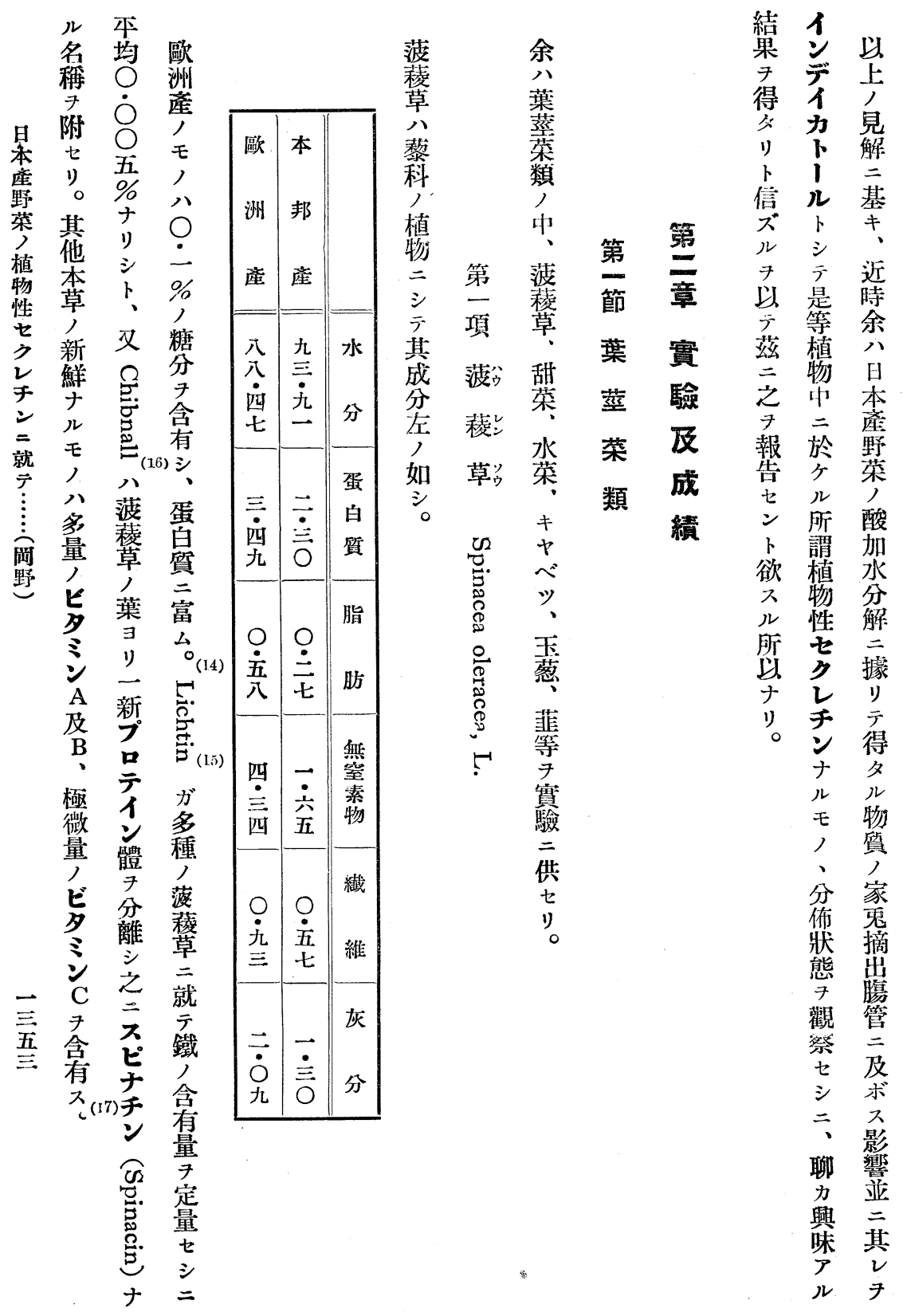




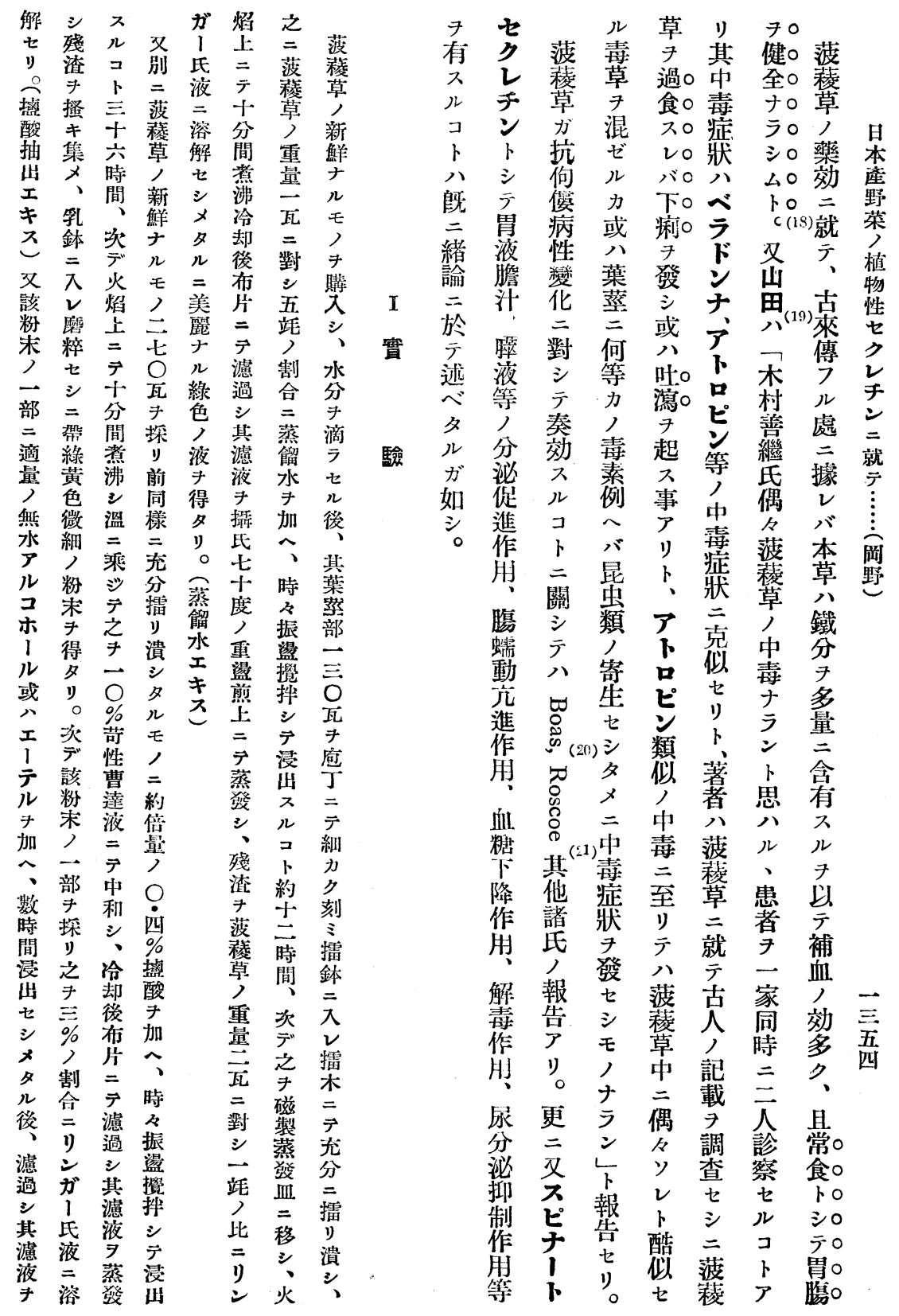




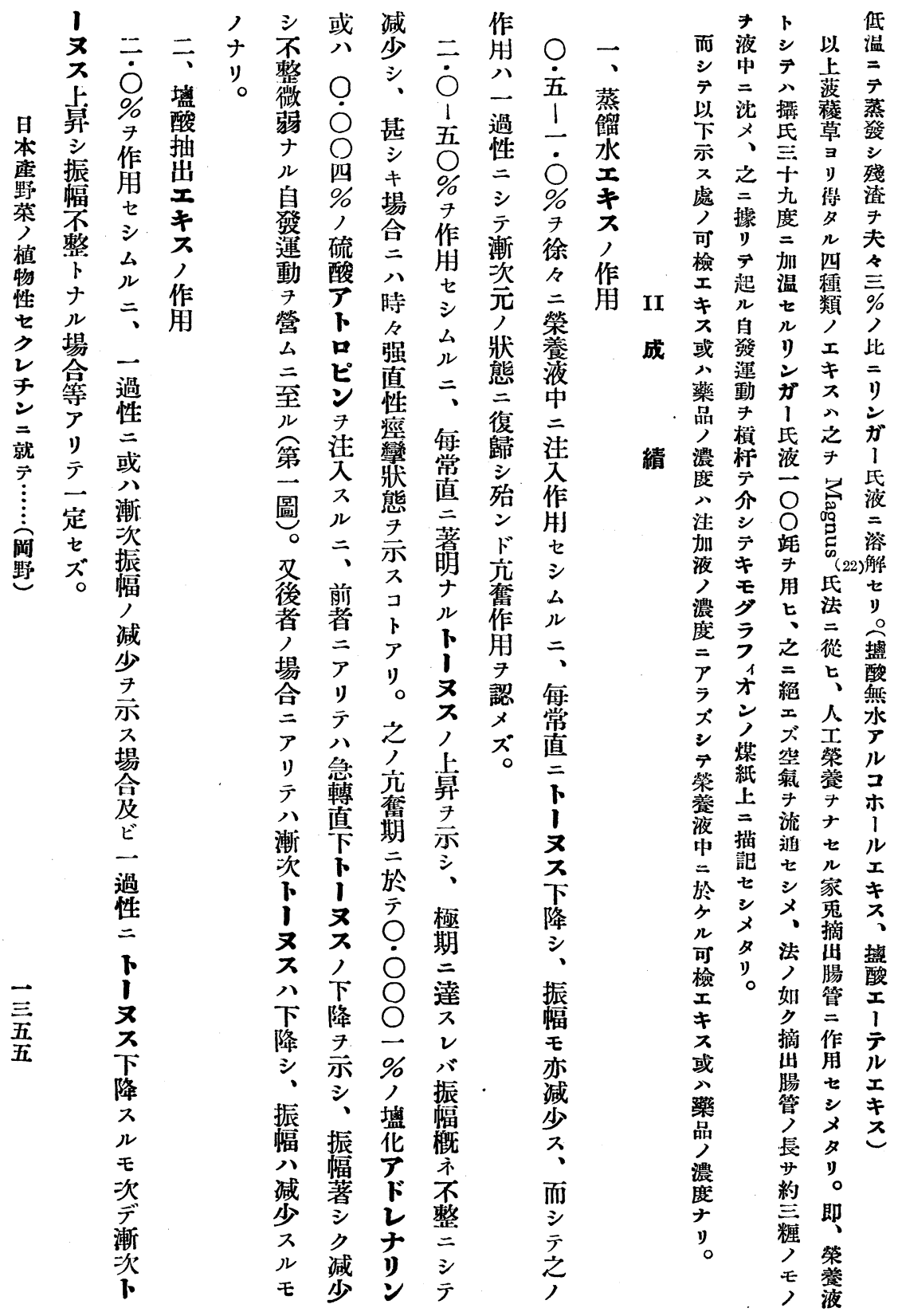




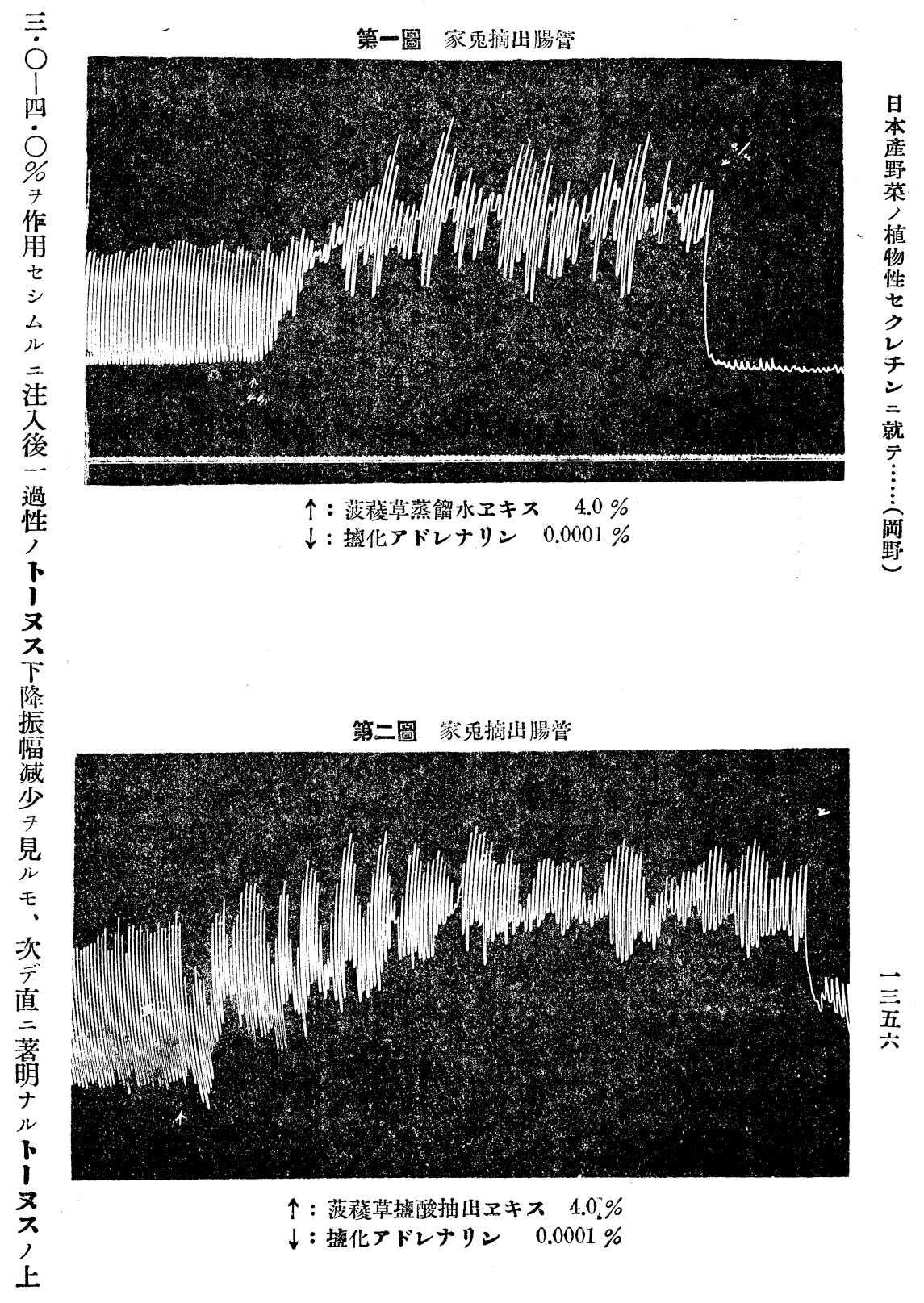




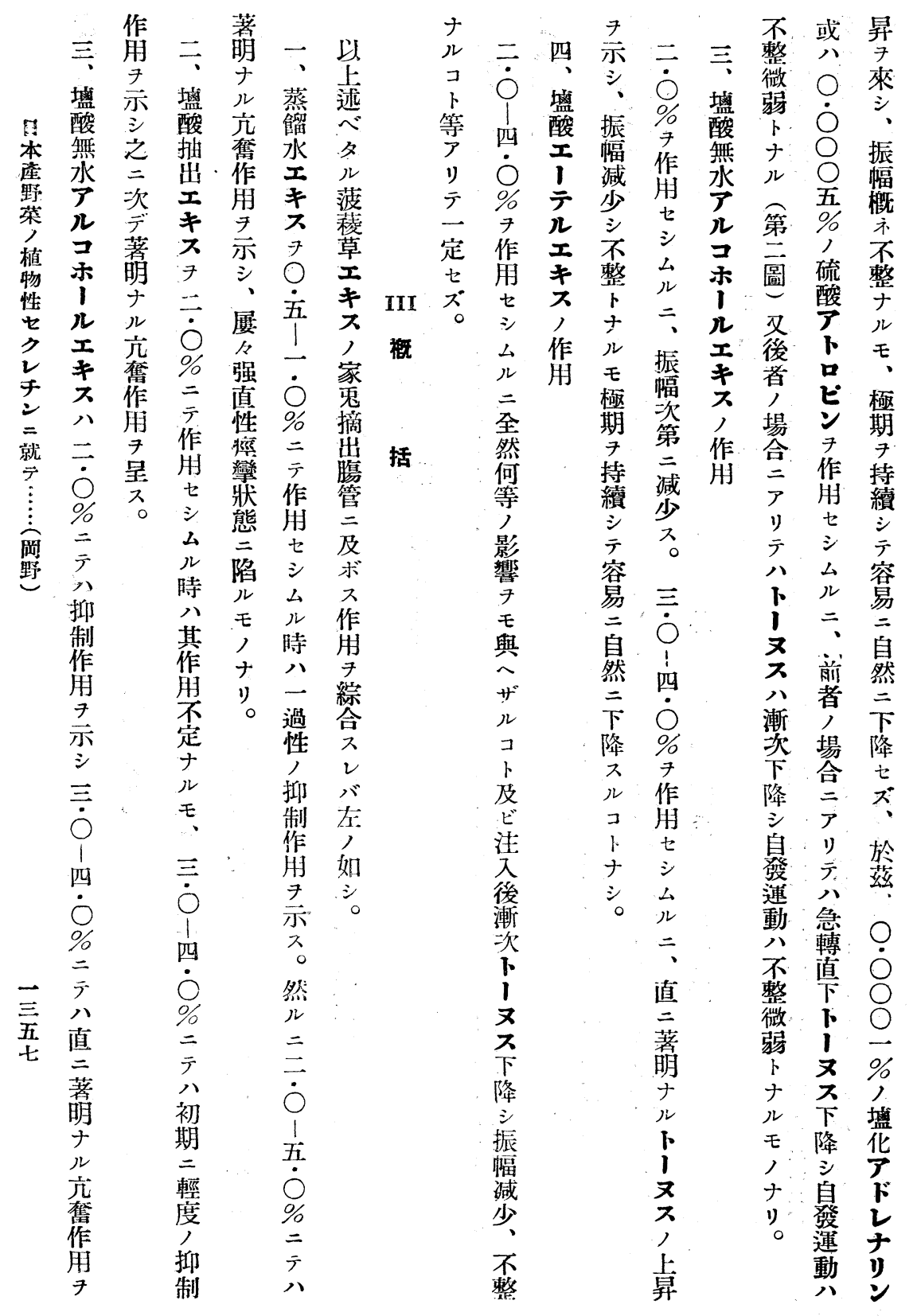




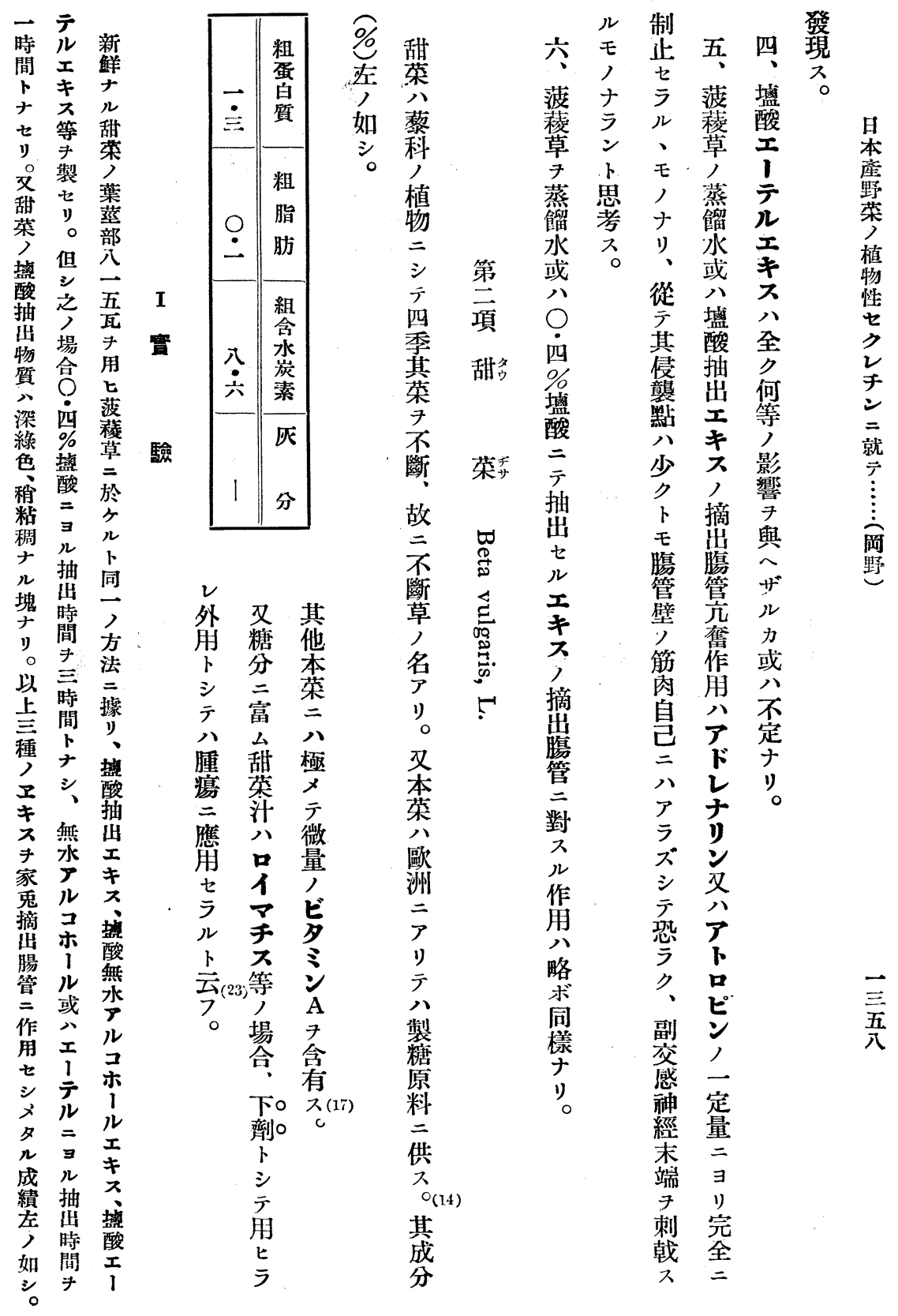




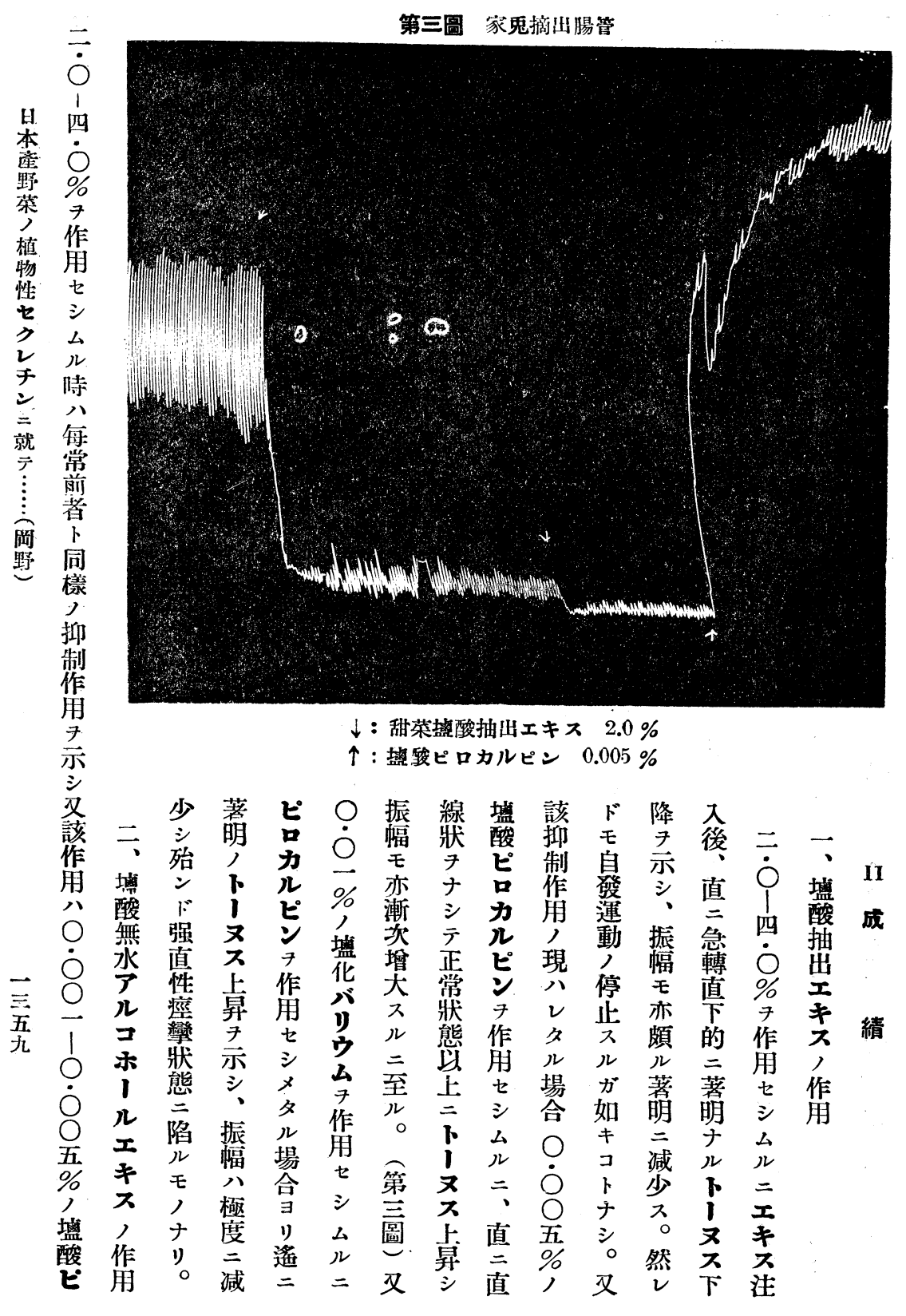




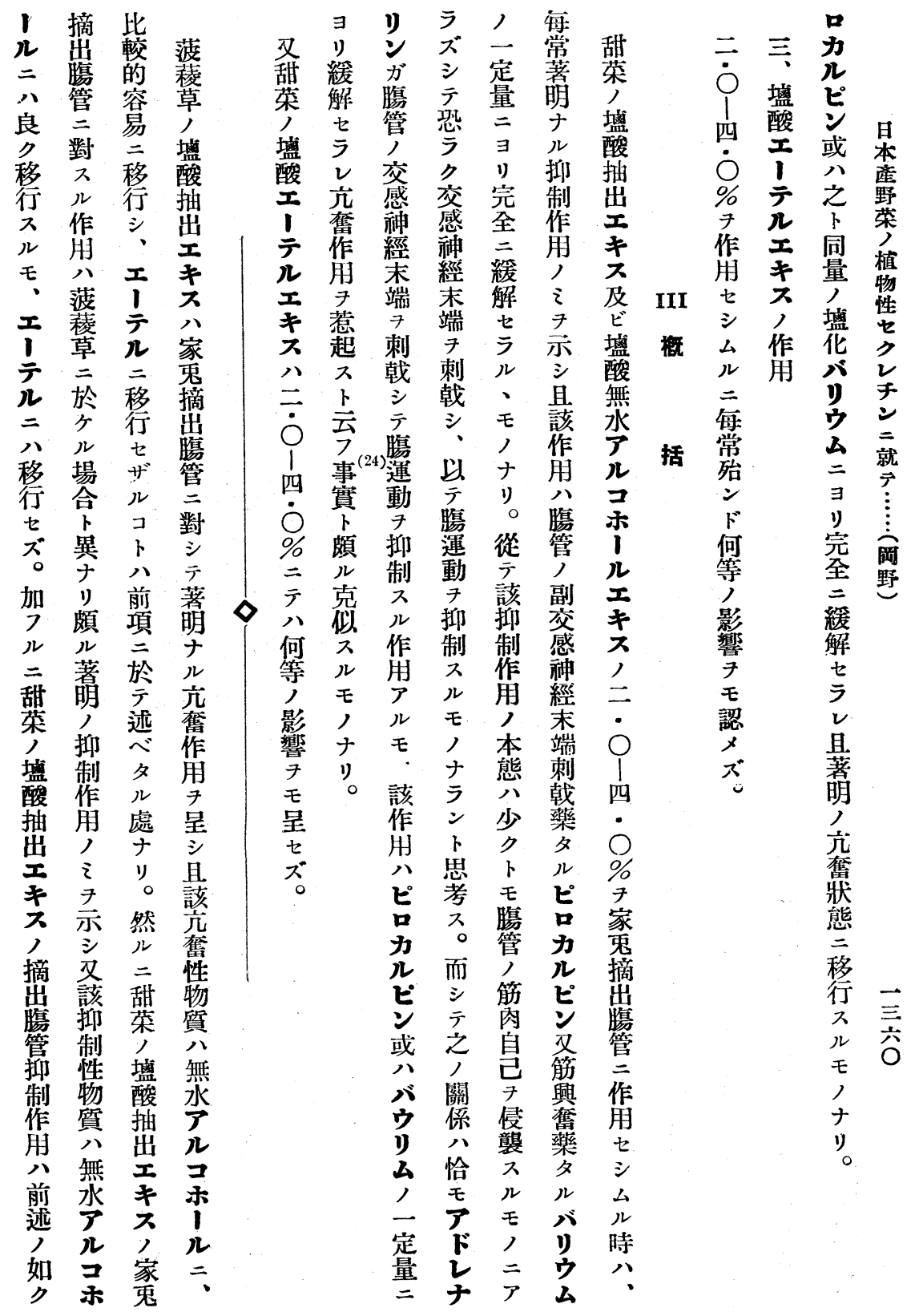



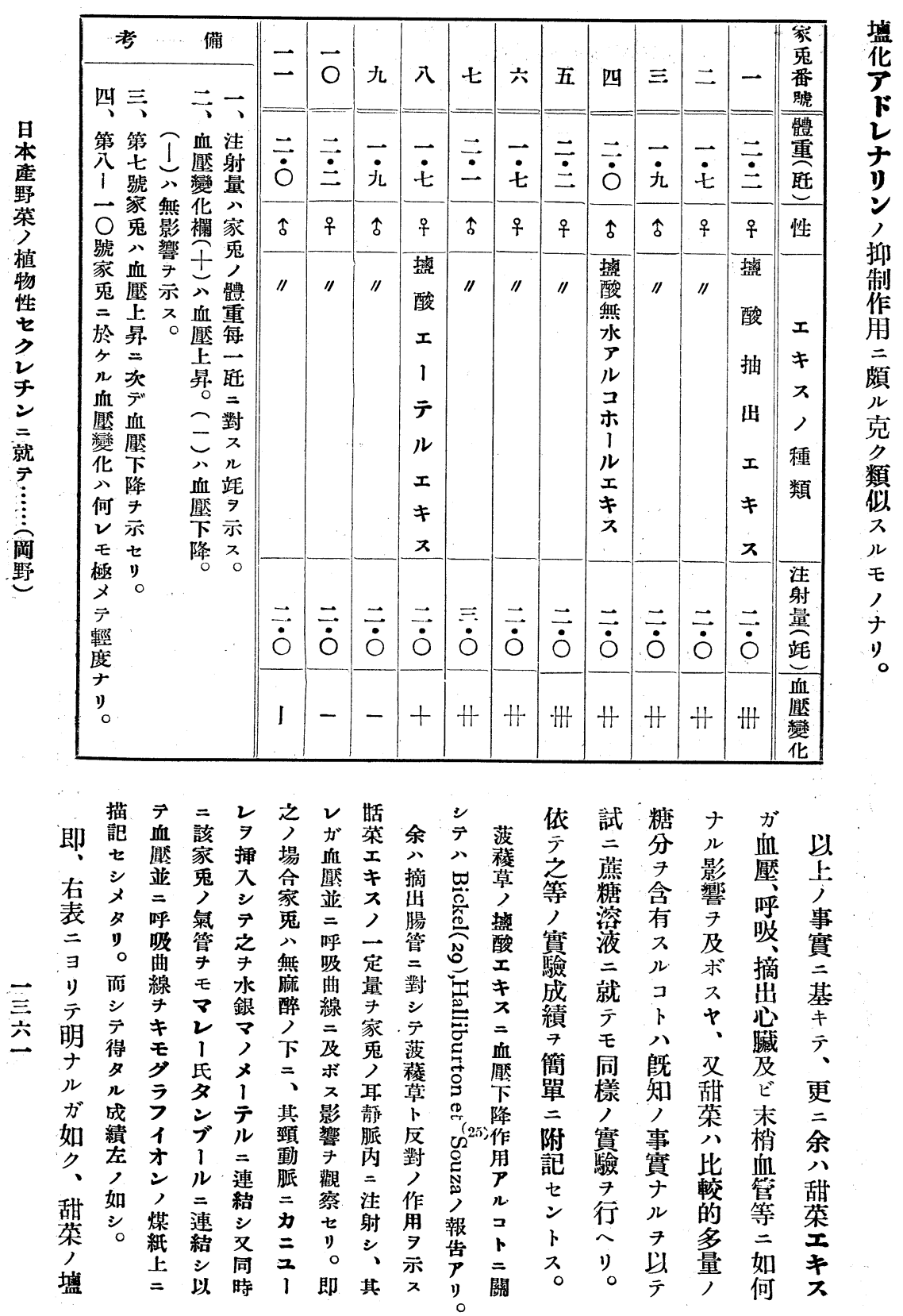


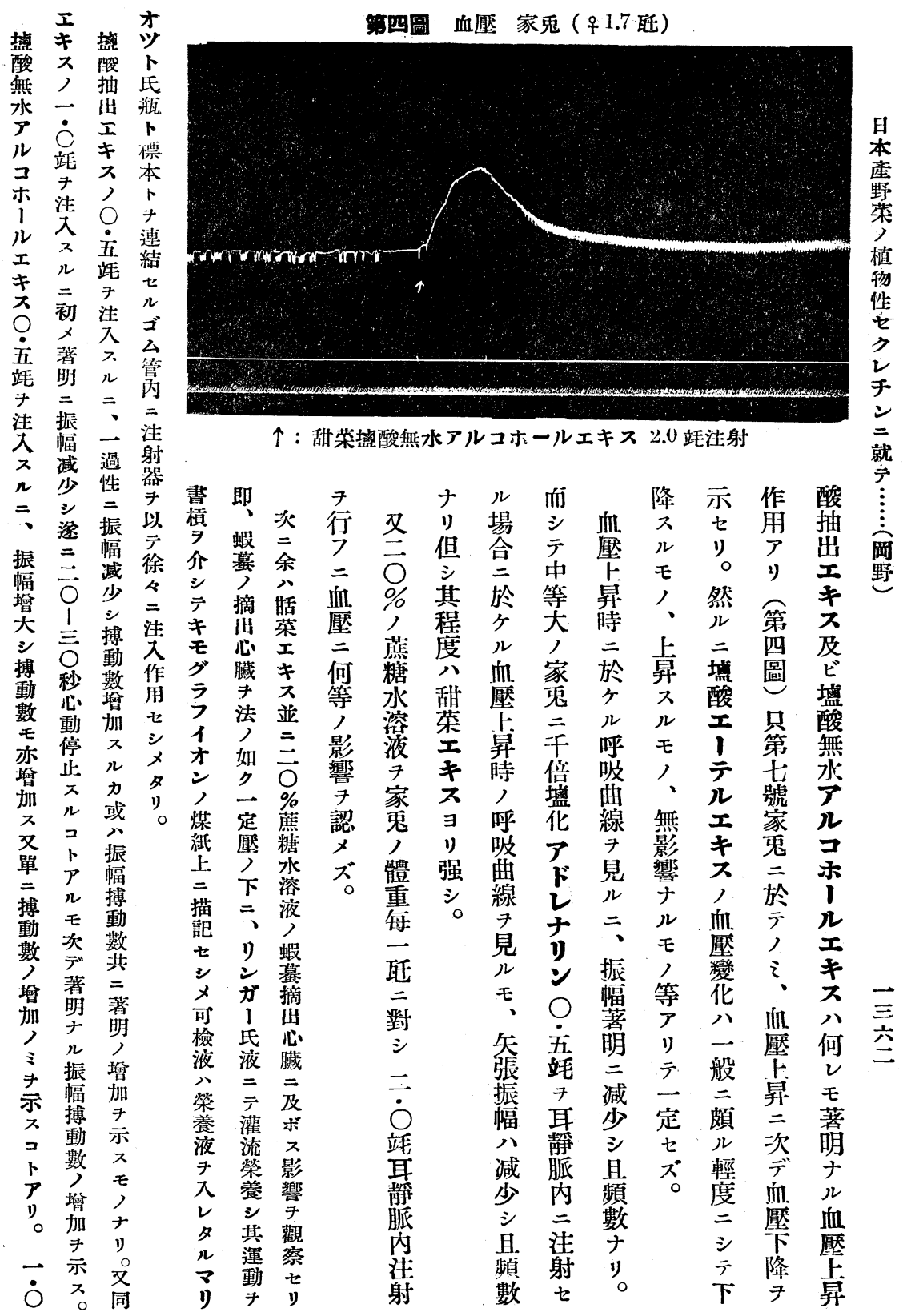


第五圖 蝦蟇抽出心䠞

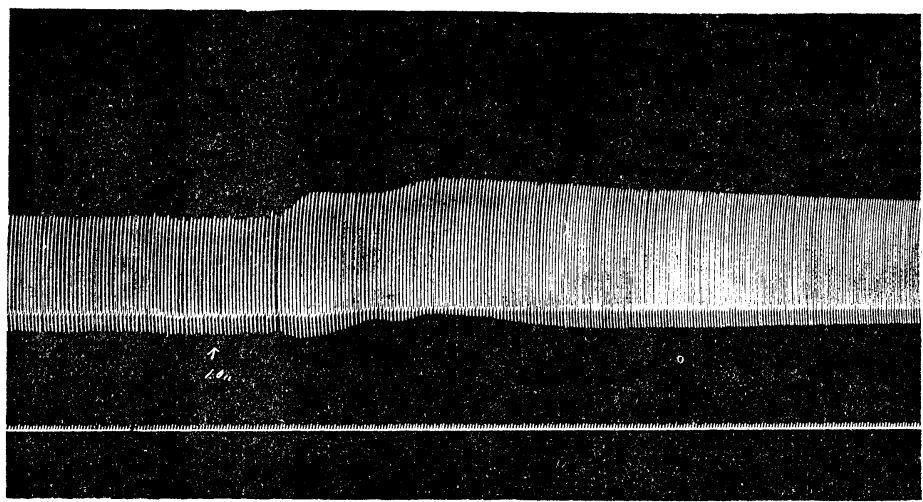

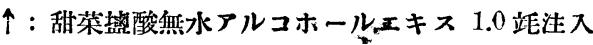

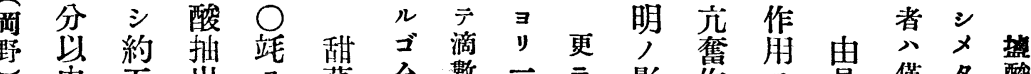

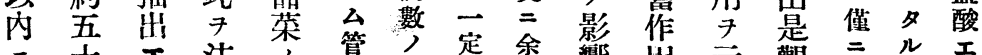

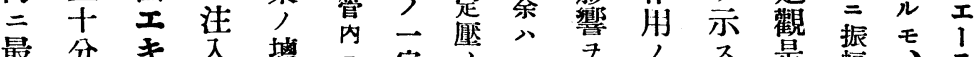

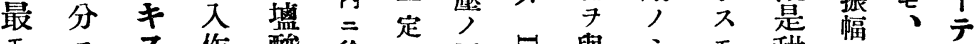

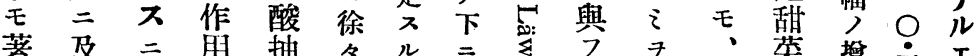
意ブアセ出

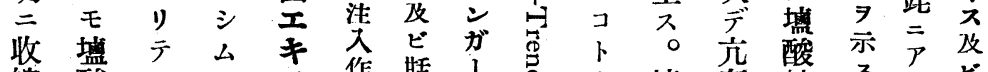

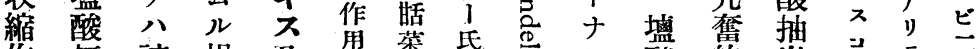

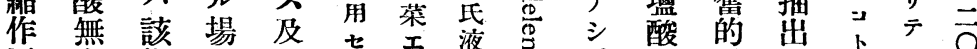
用 水 作 合 ビ シ

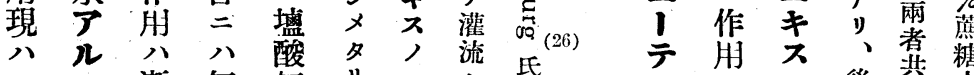

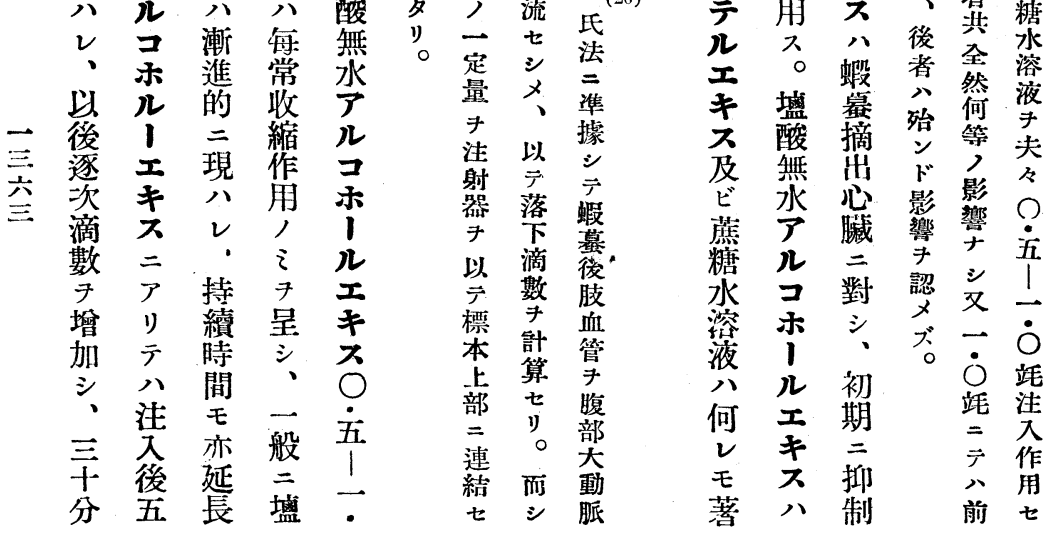




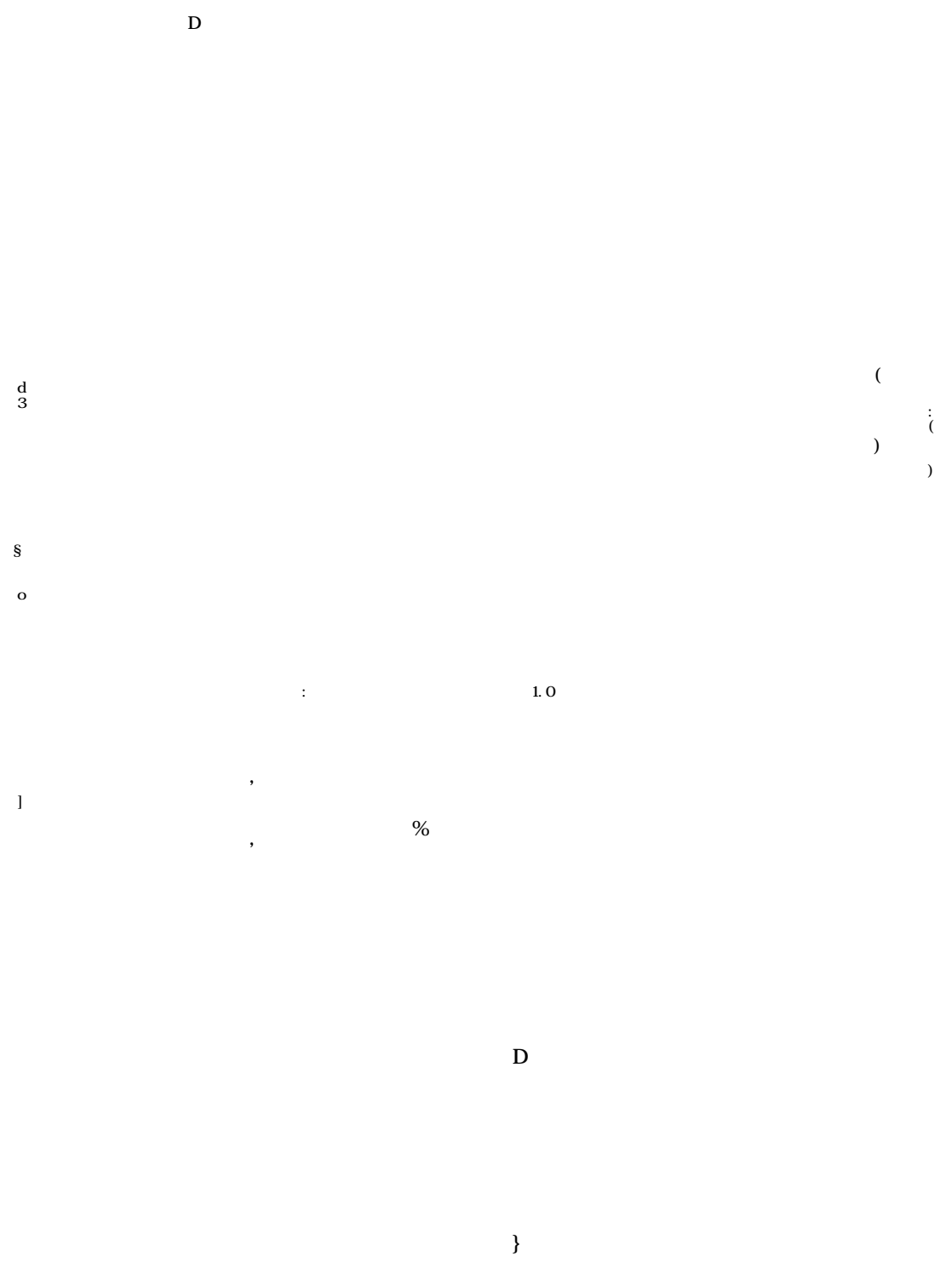




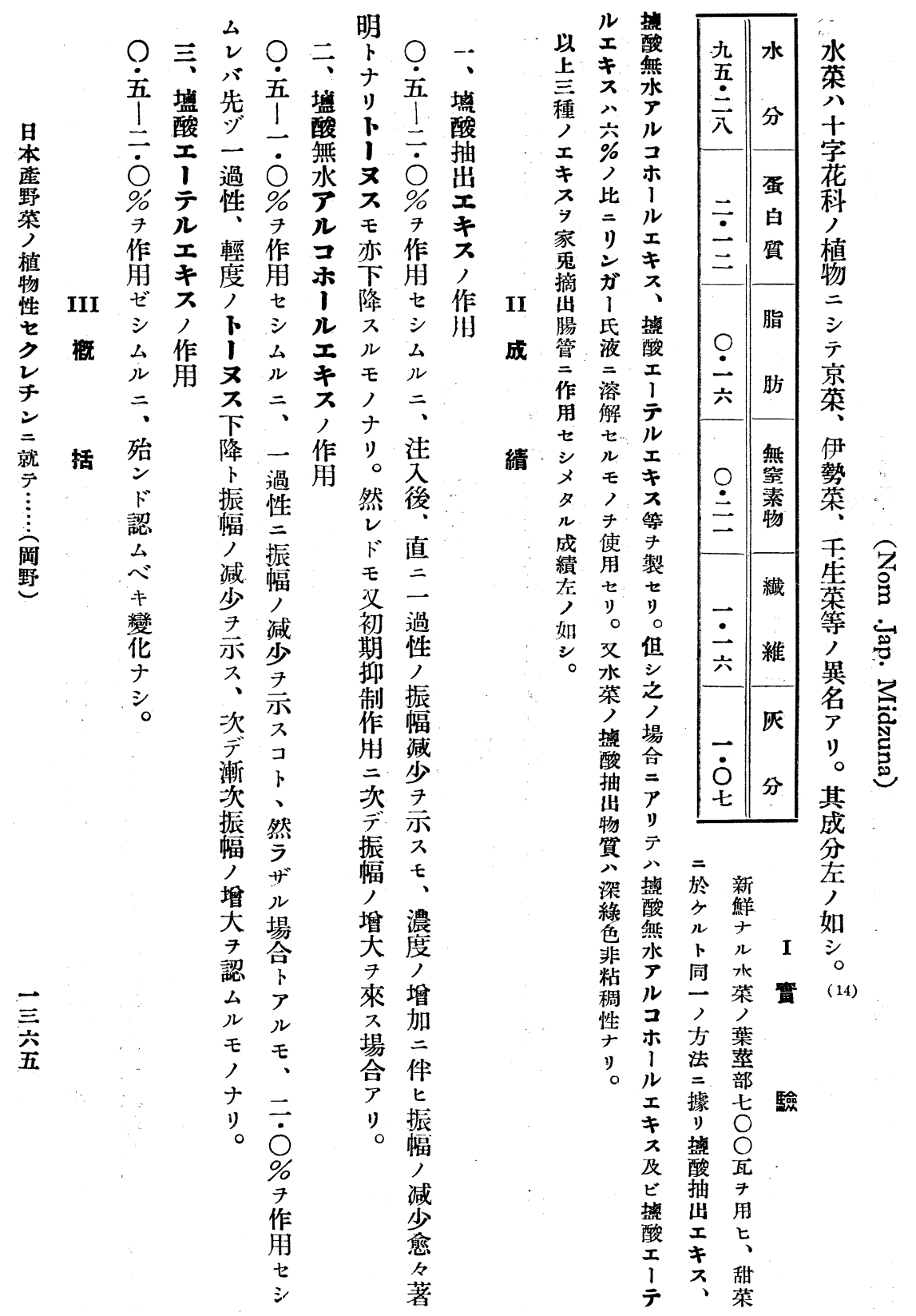




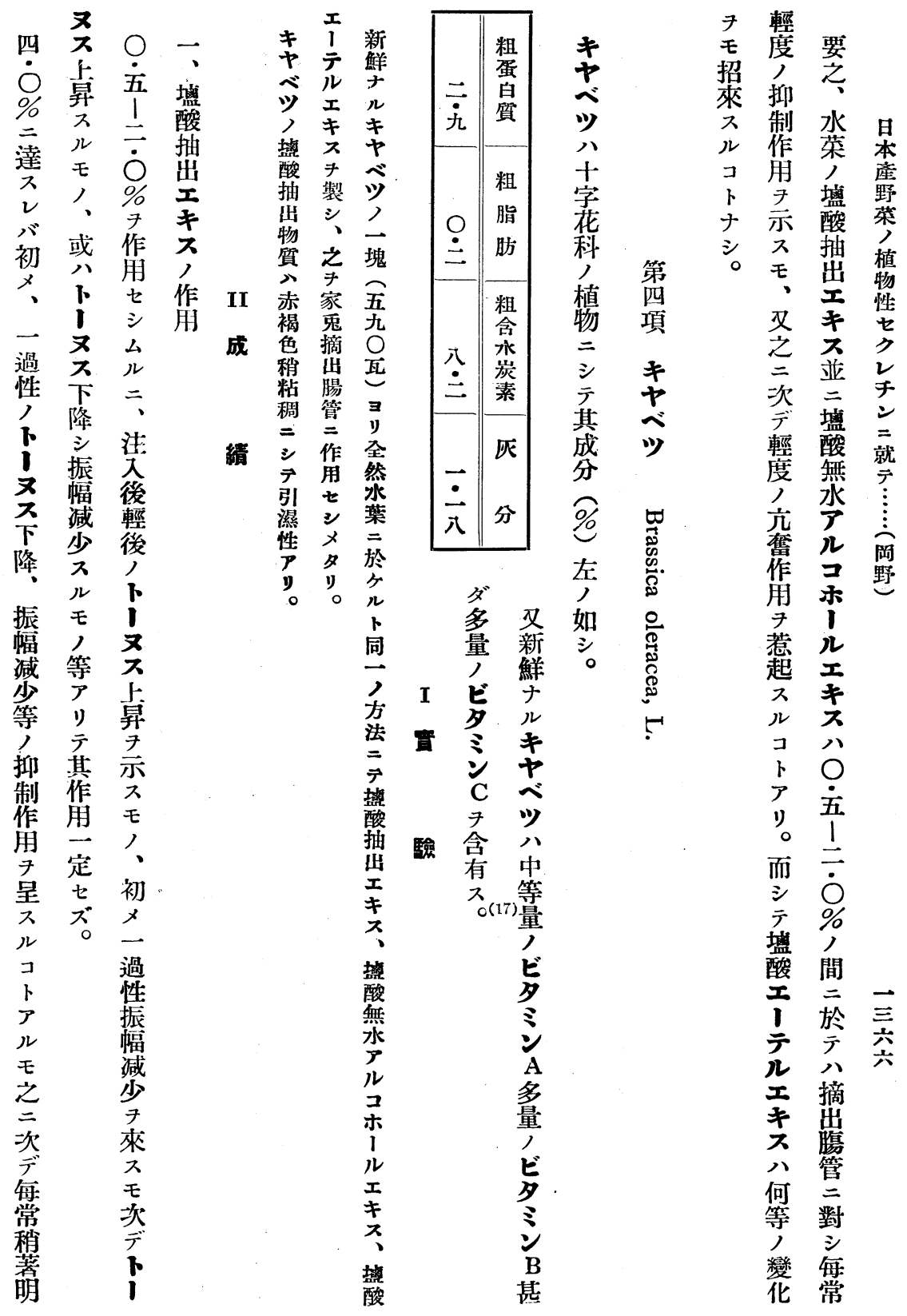




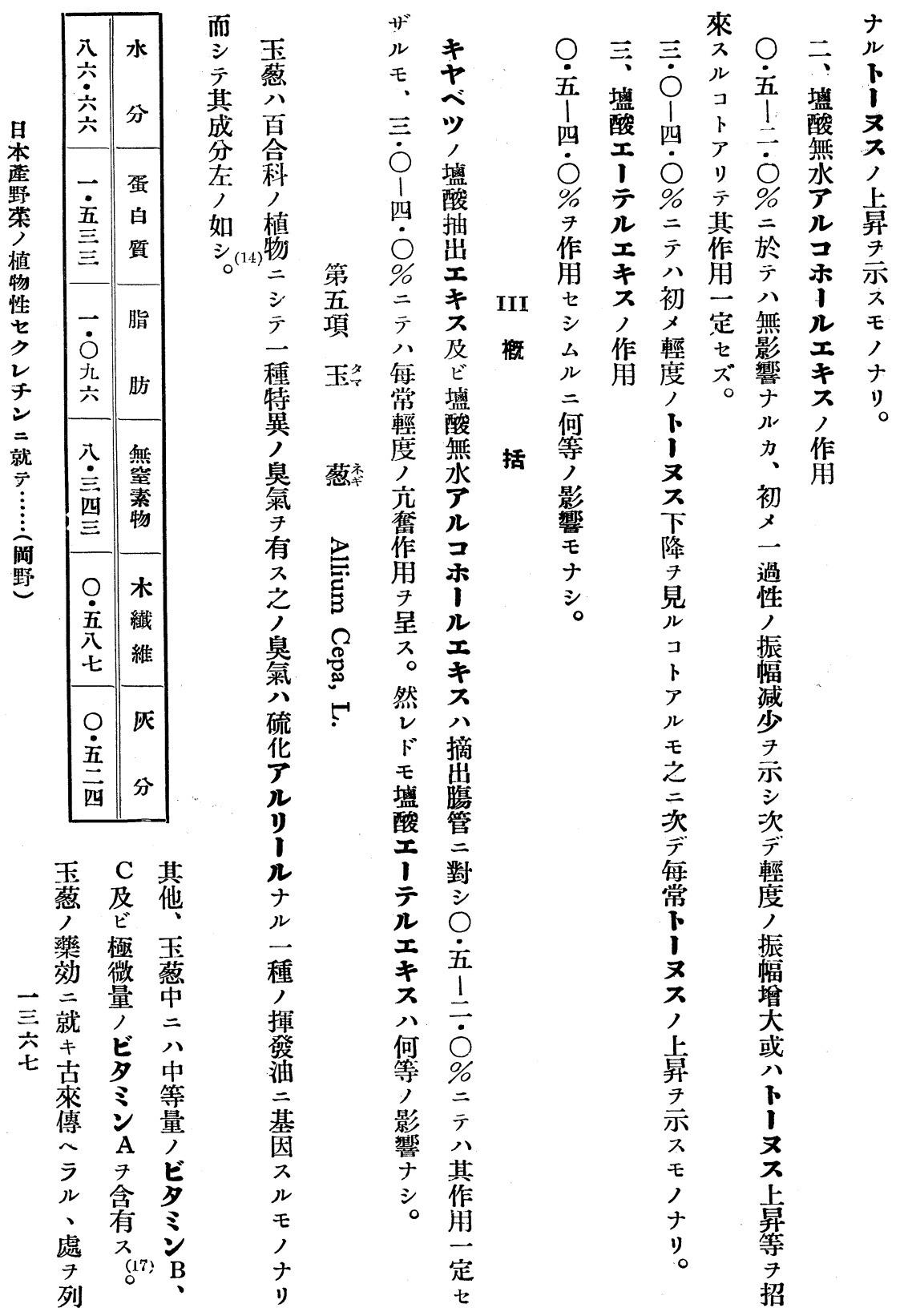




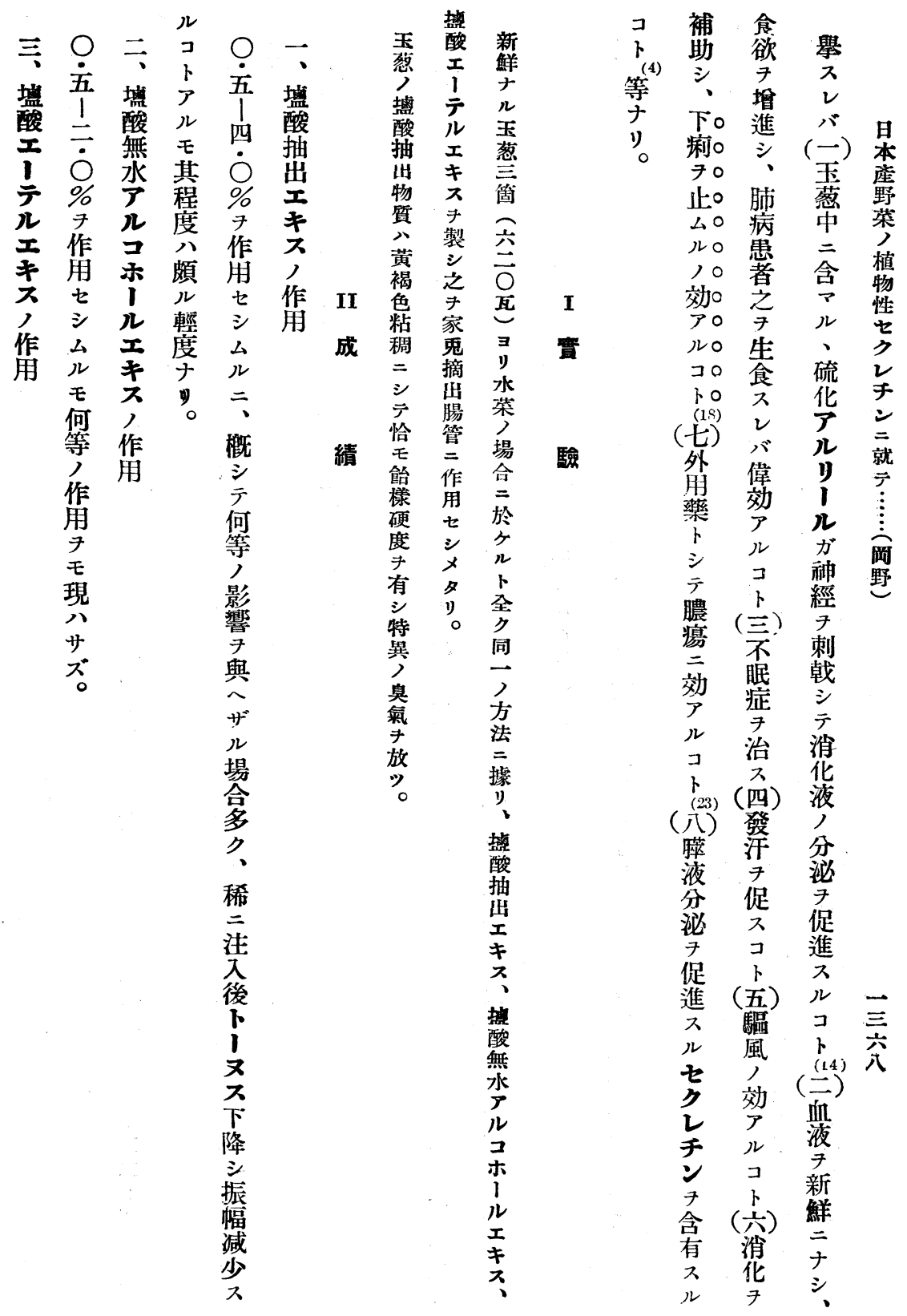




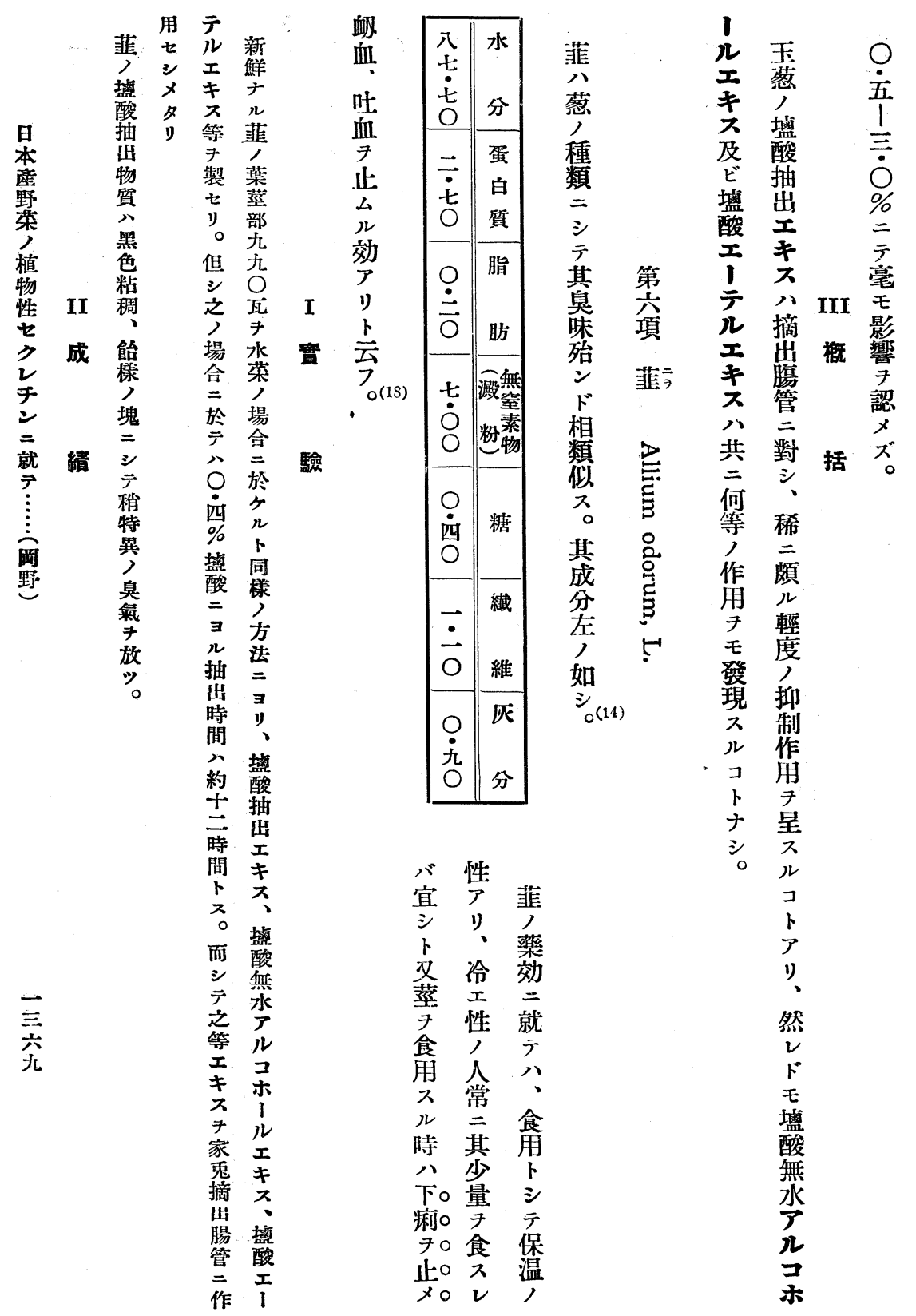




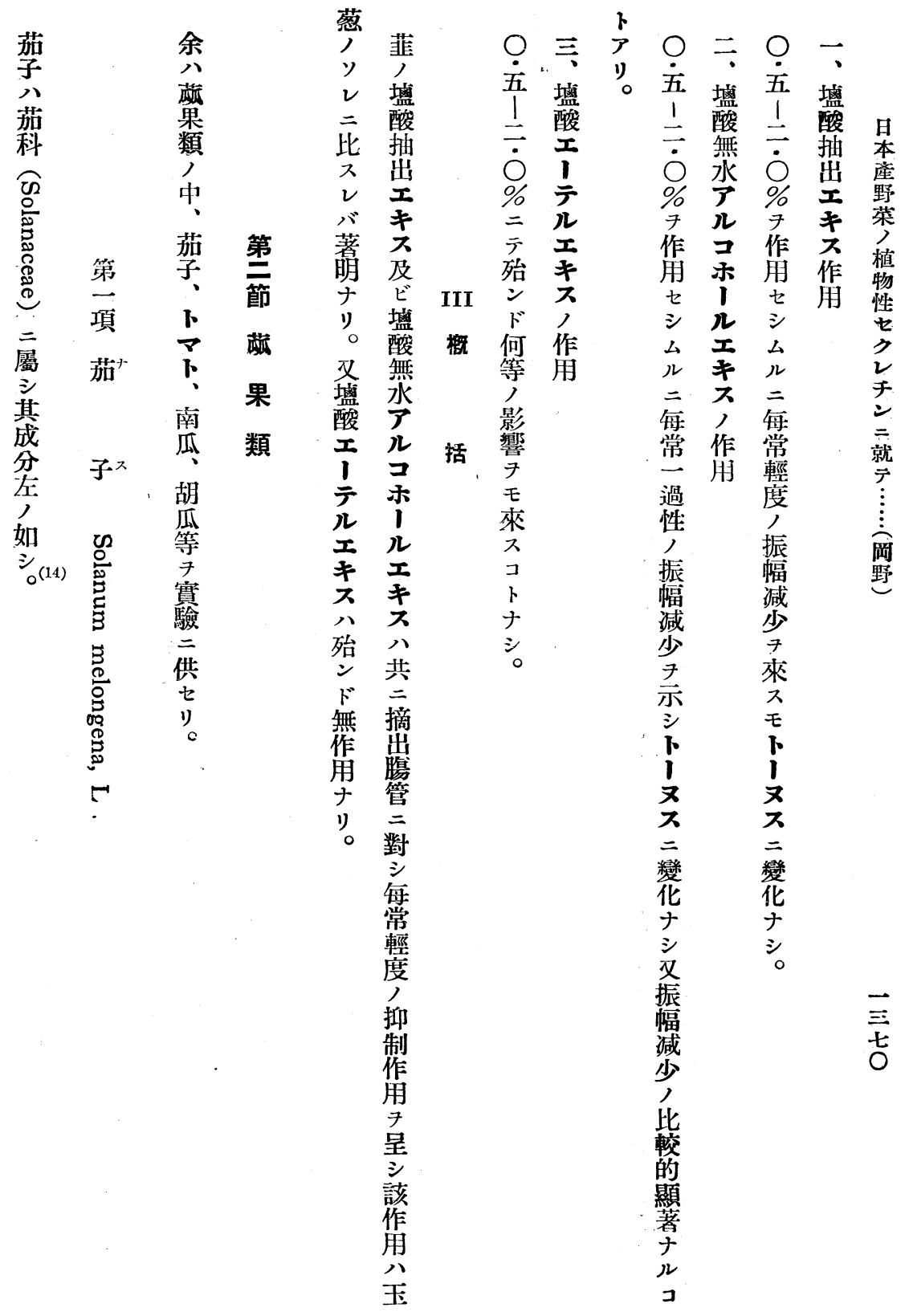




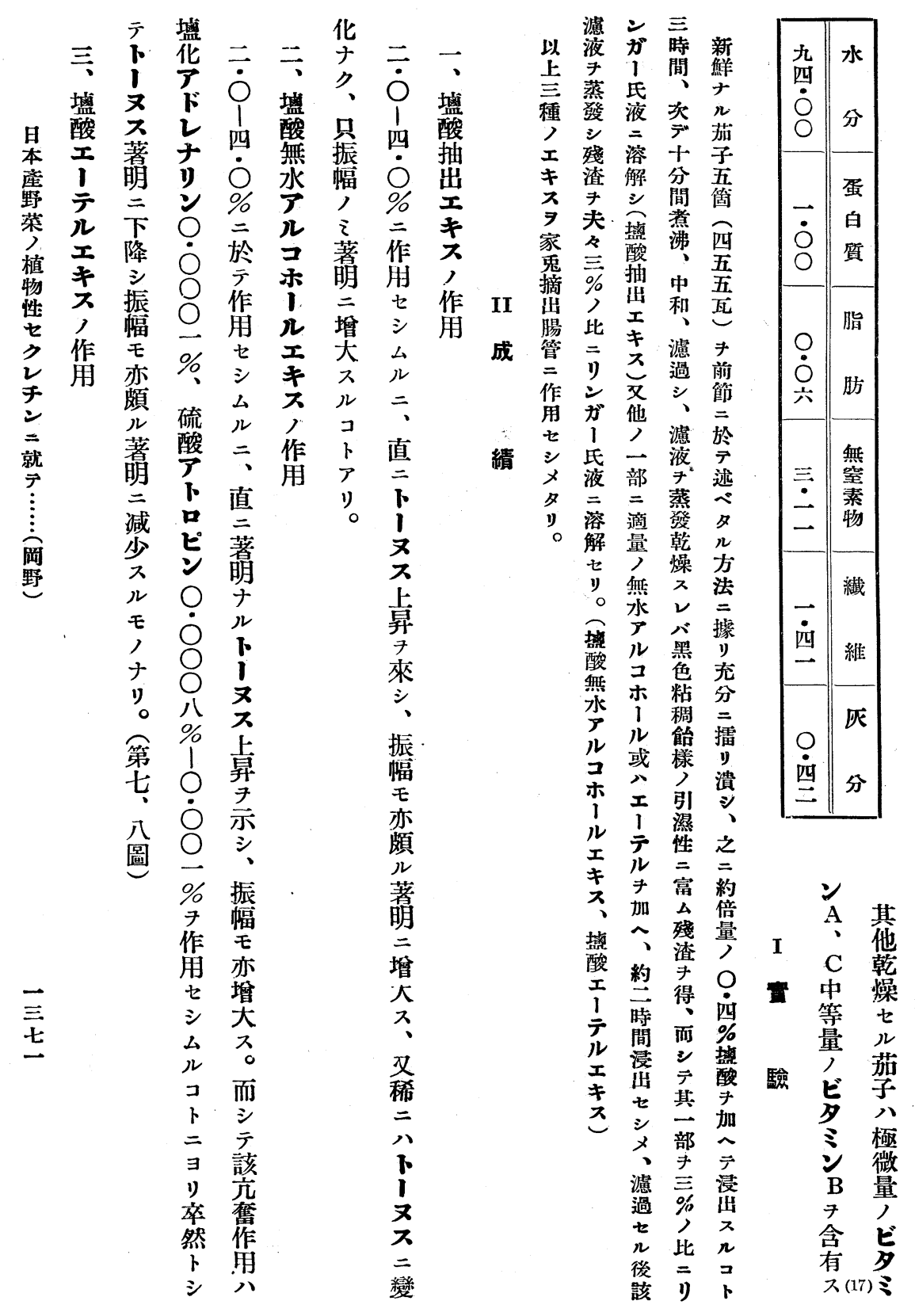




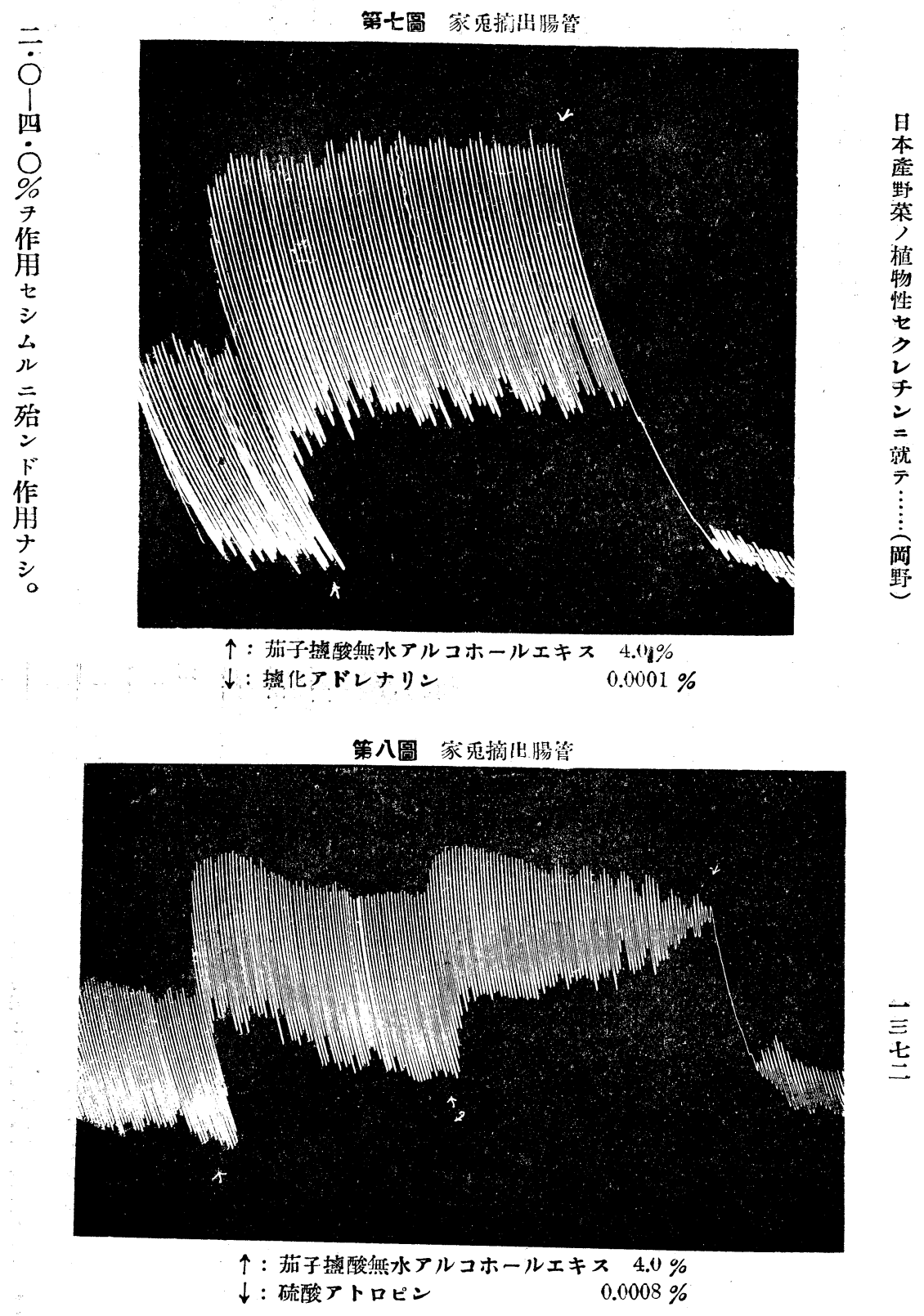




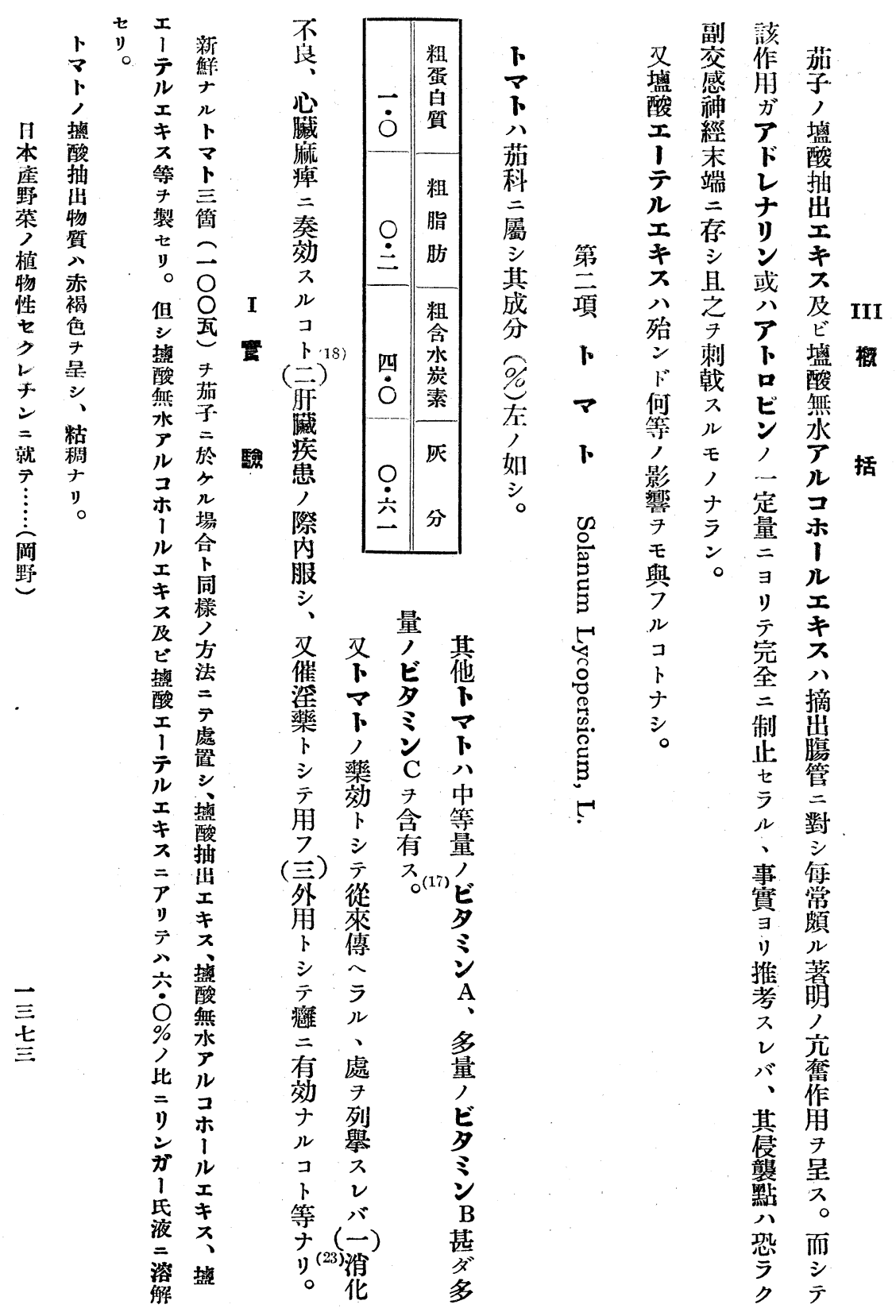


第九圖 家鬼摘组腸管
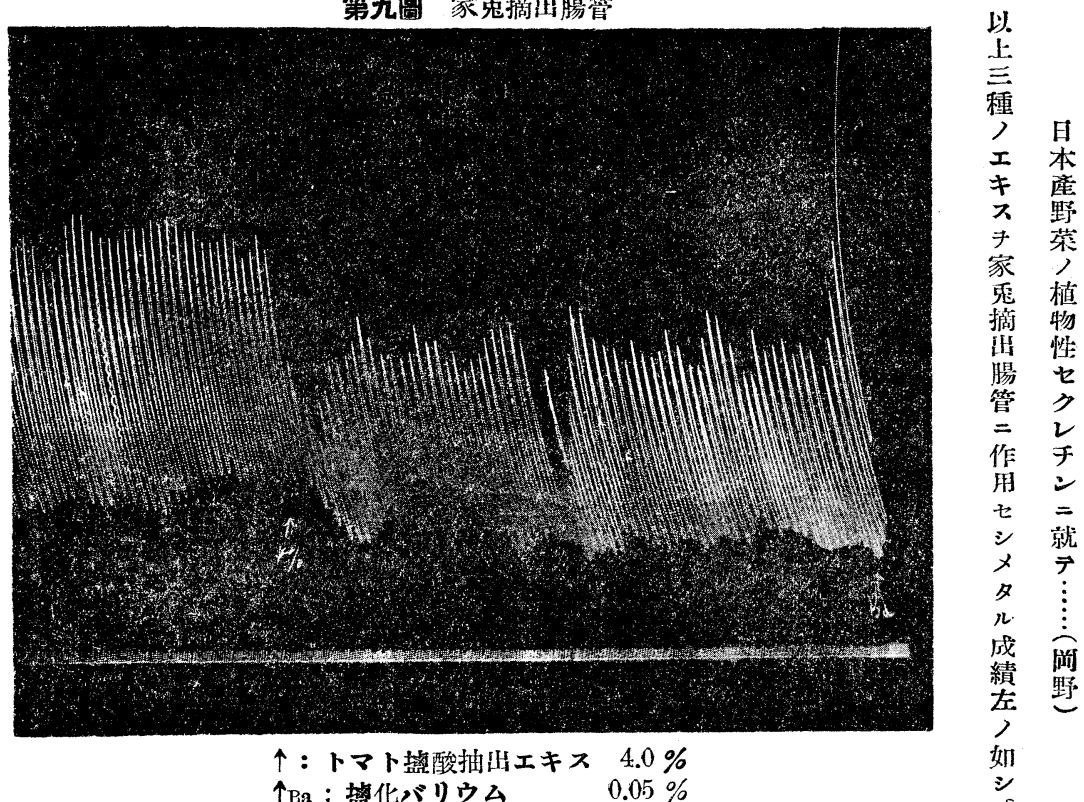

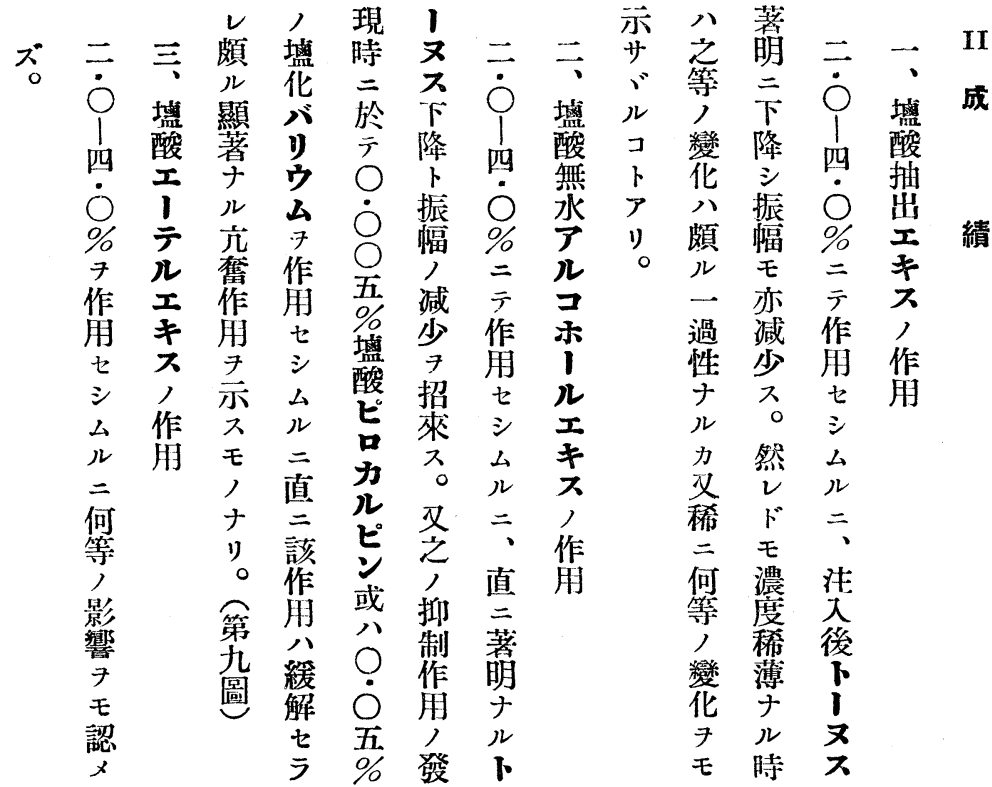




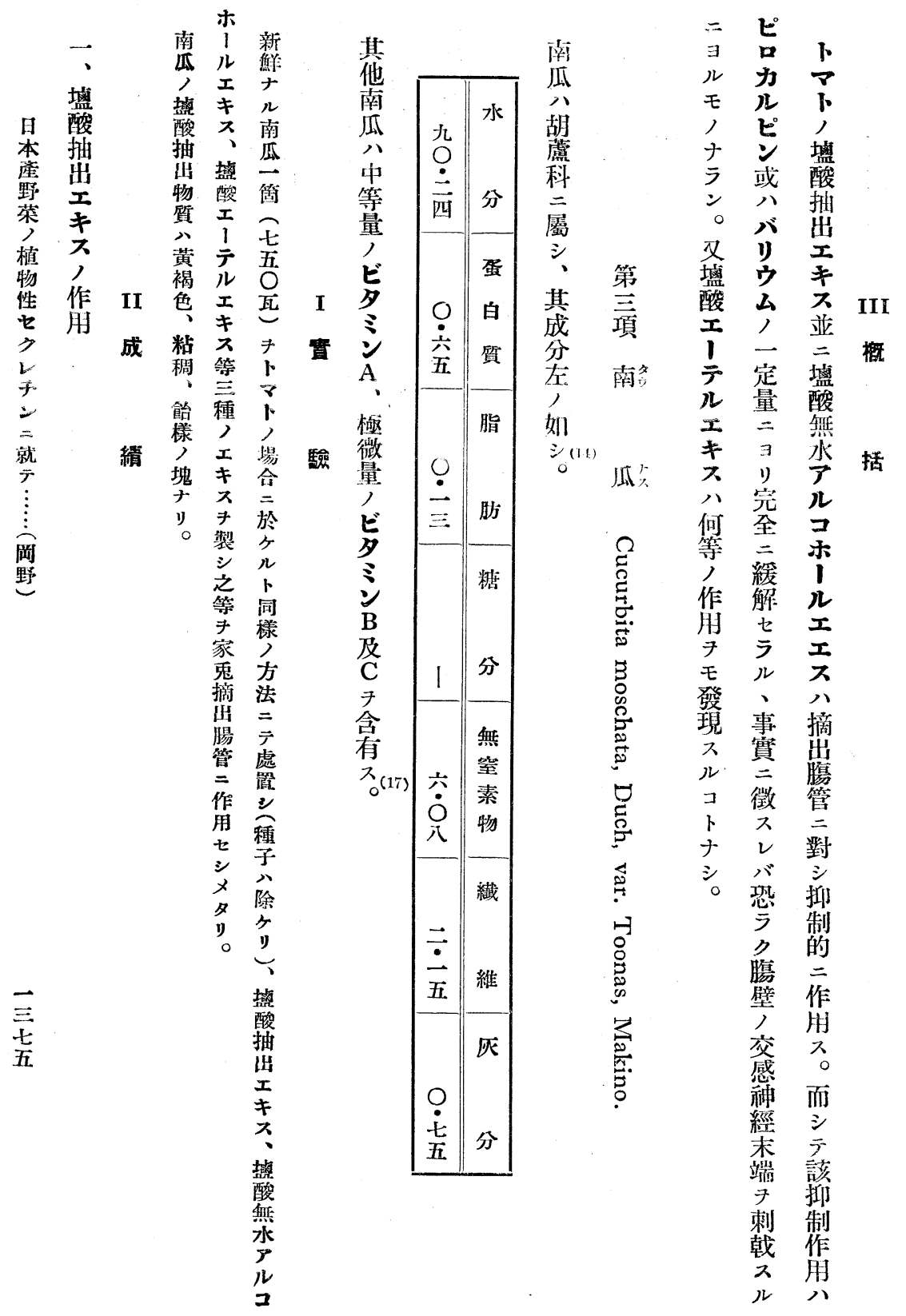




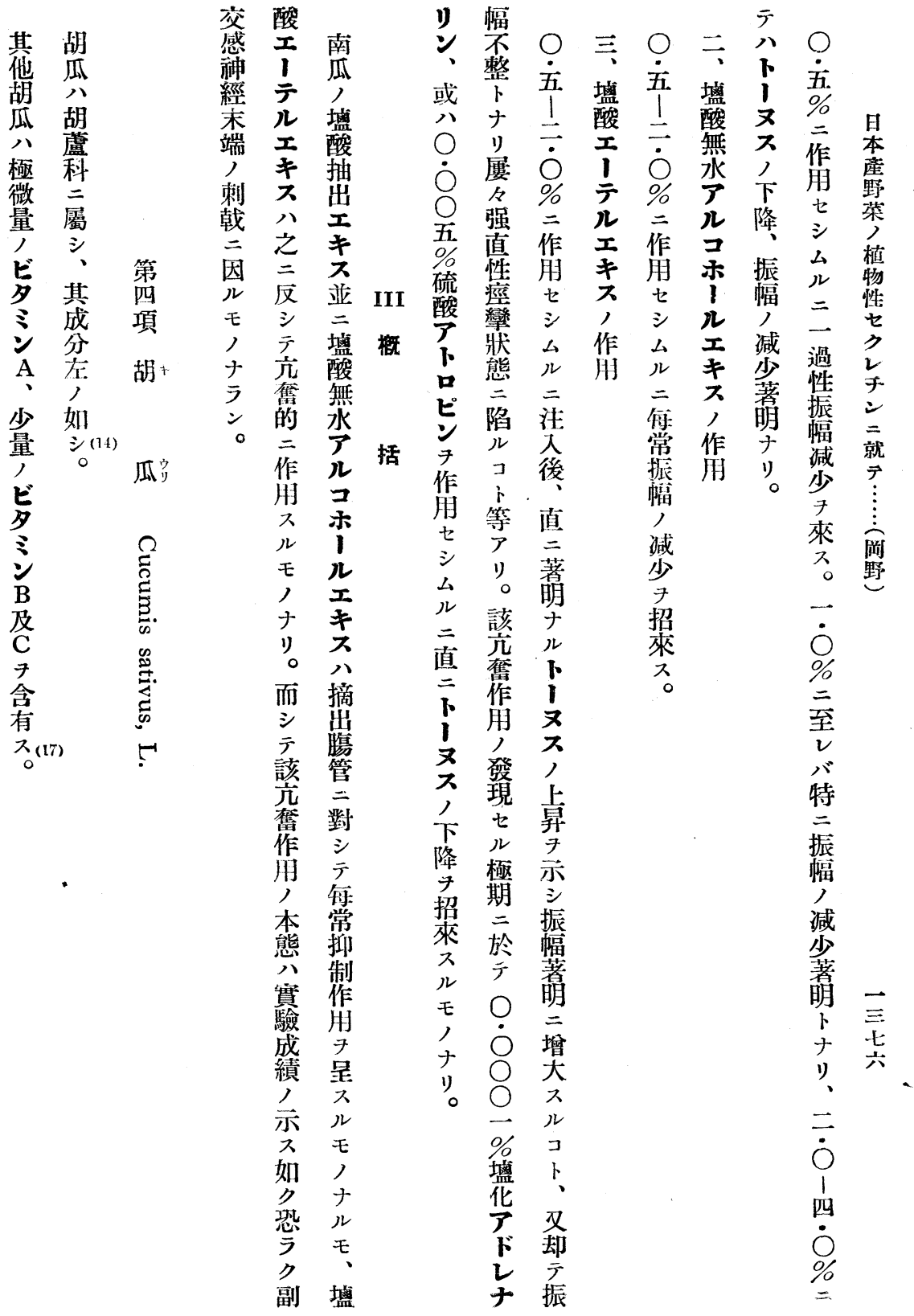




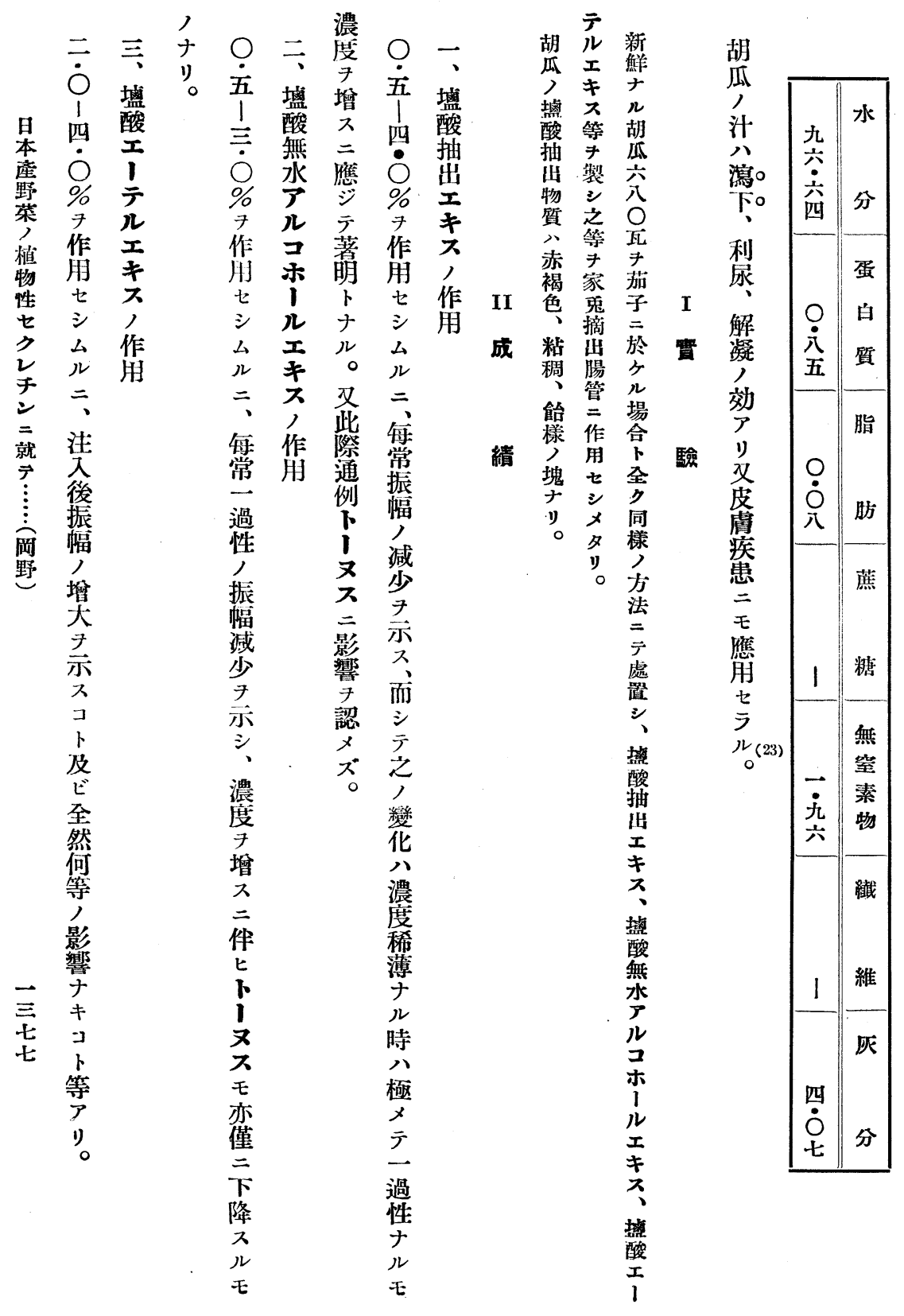




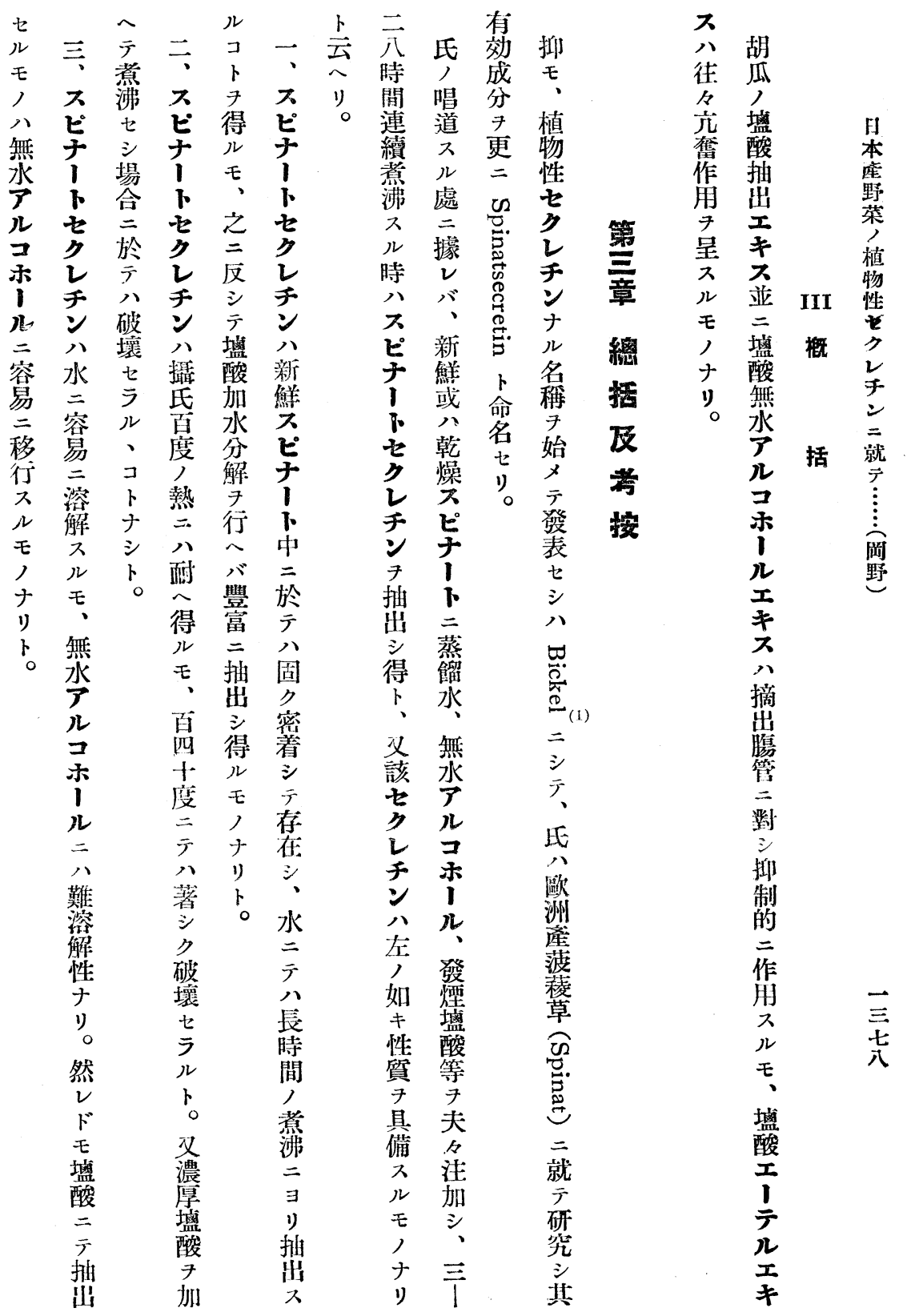




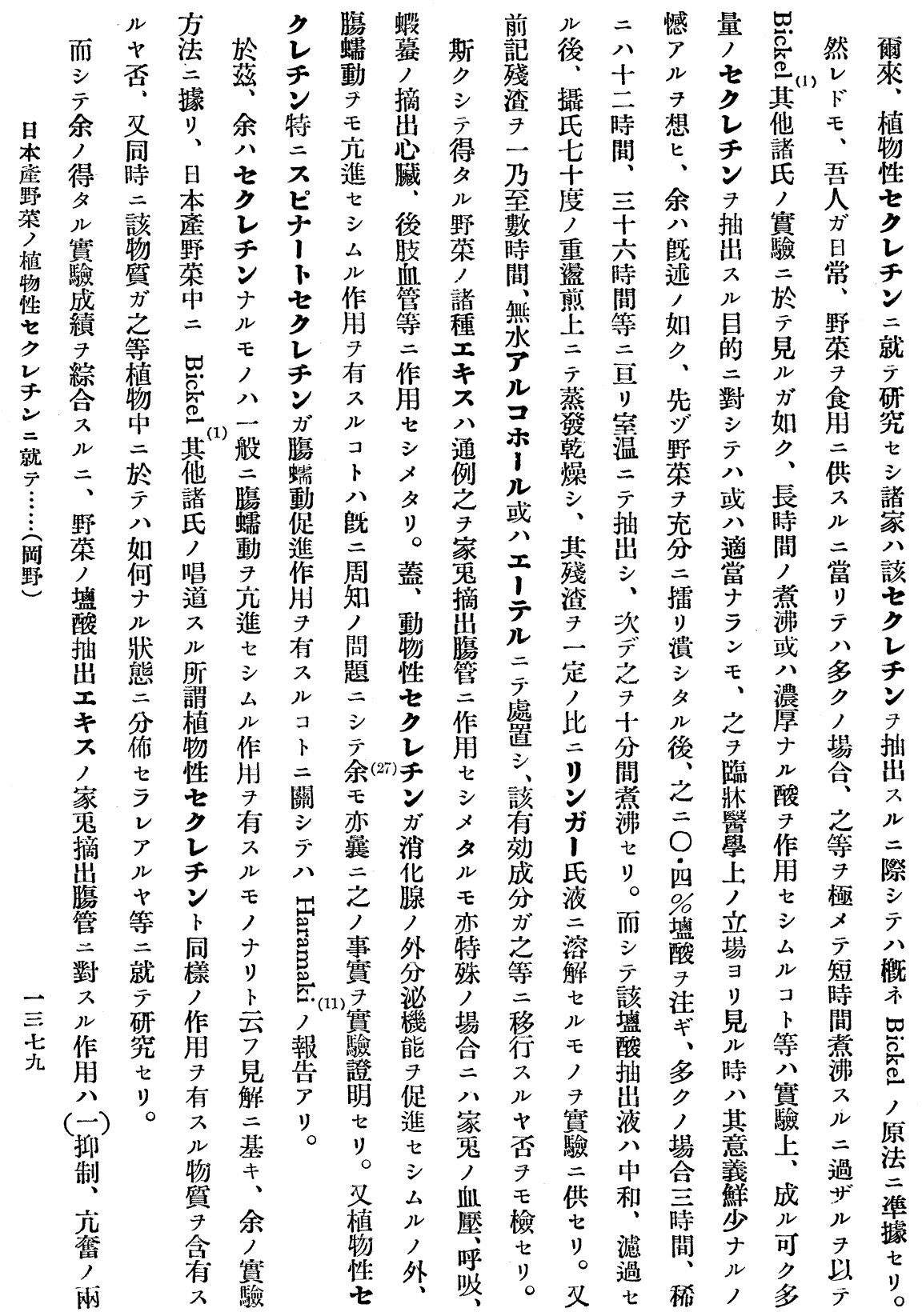




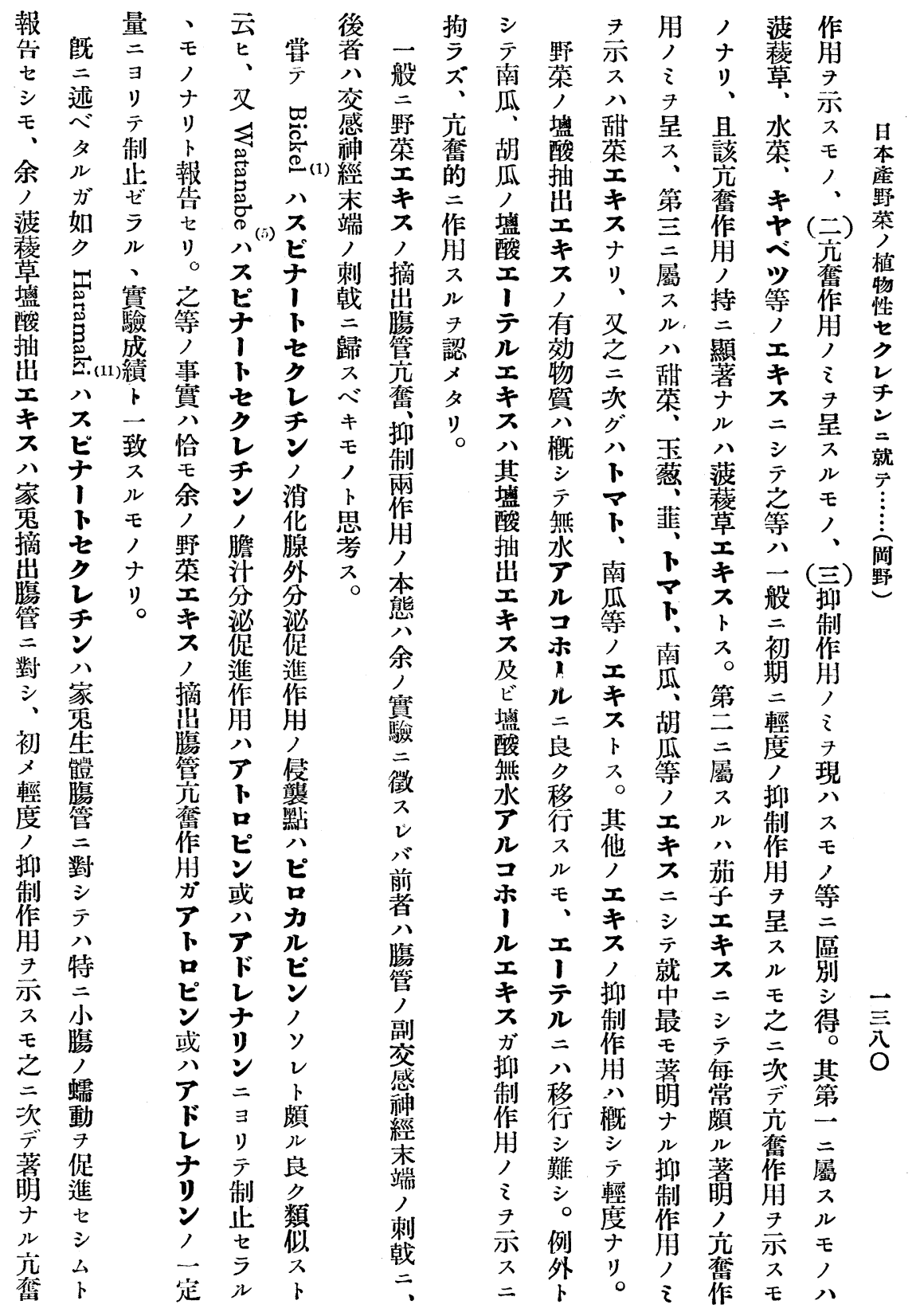




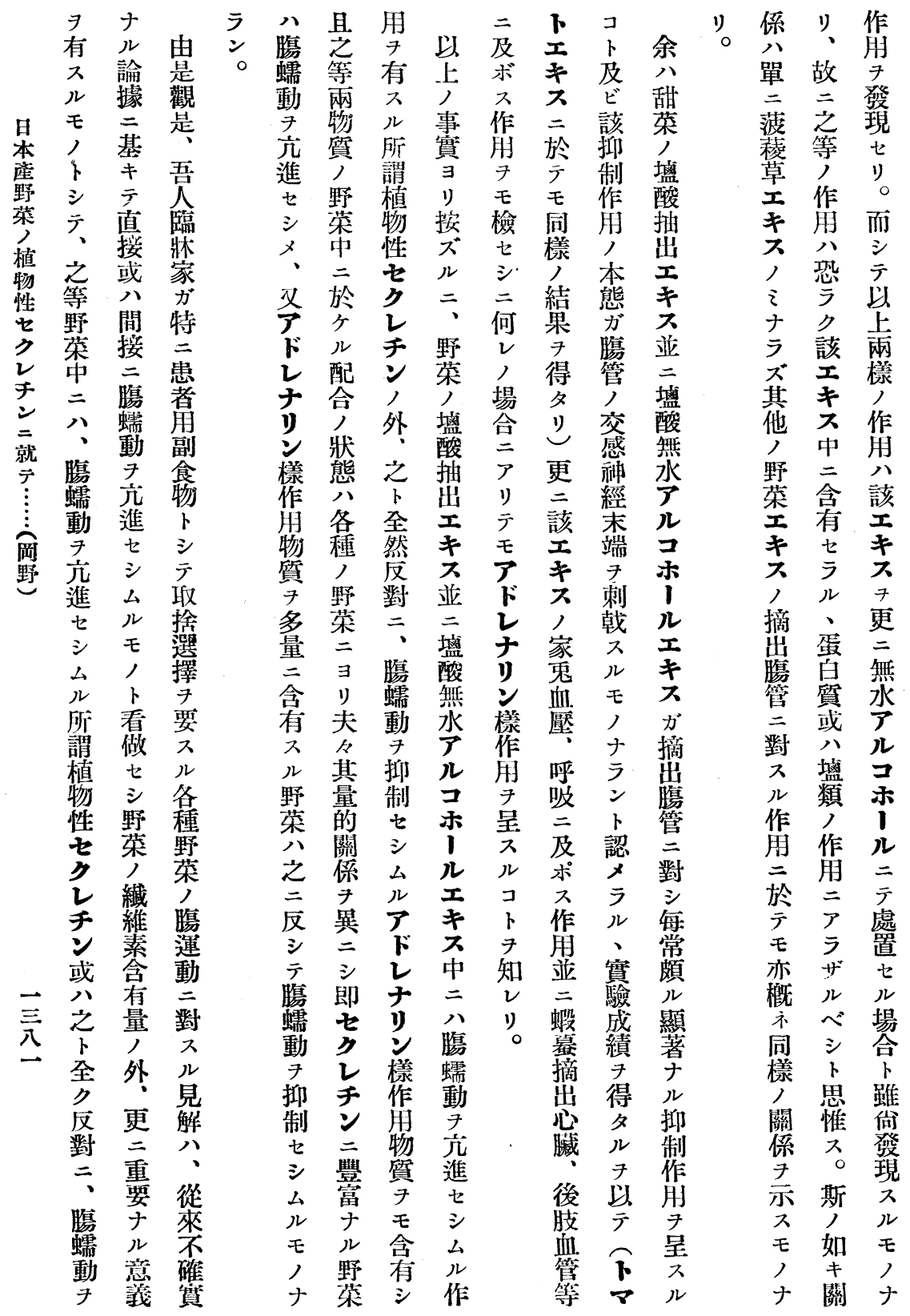




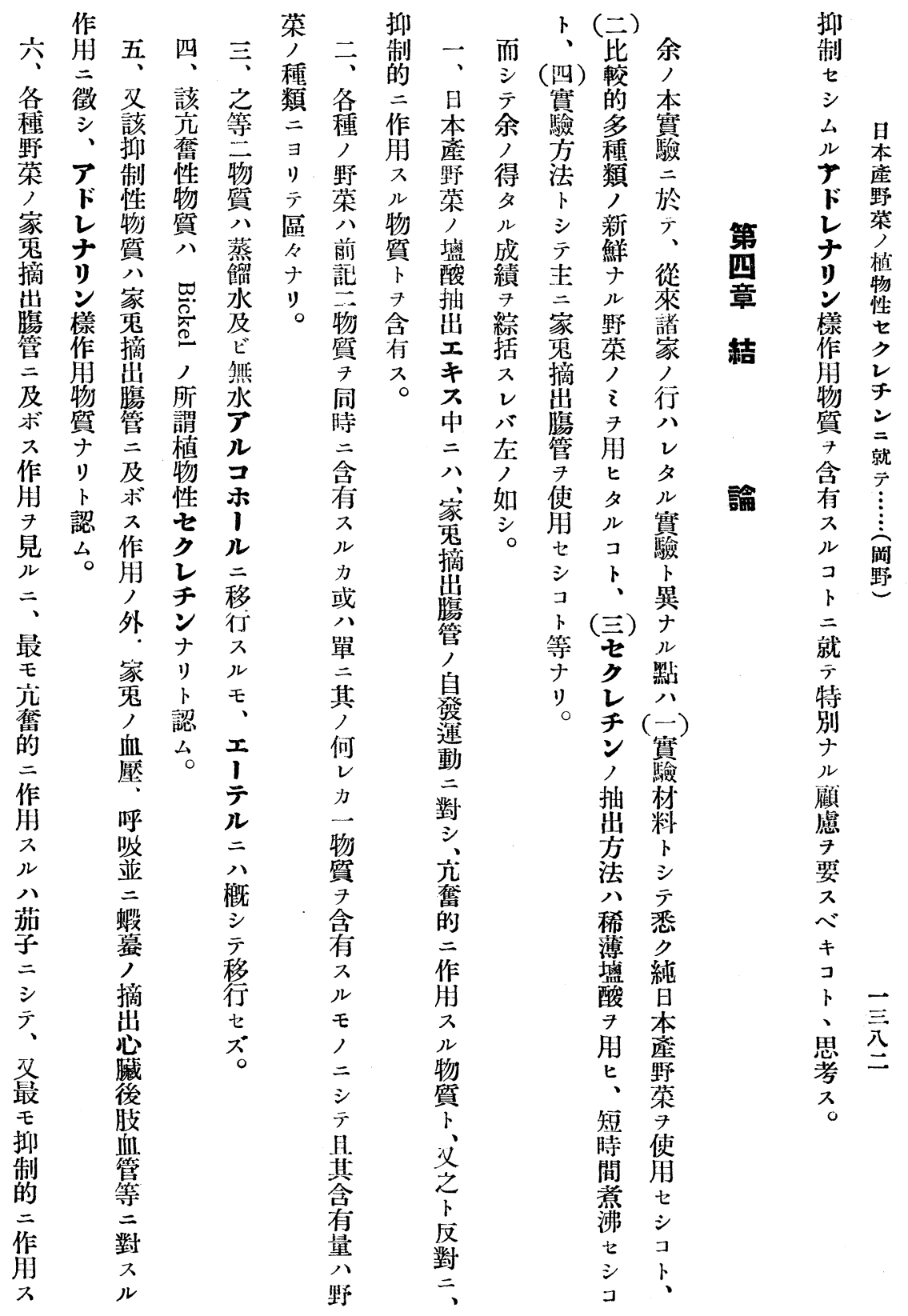



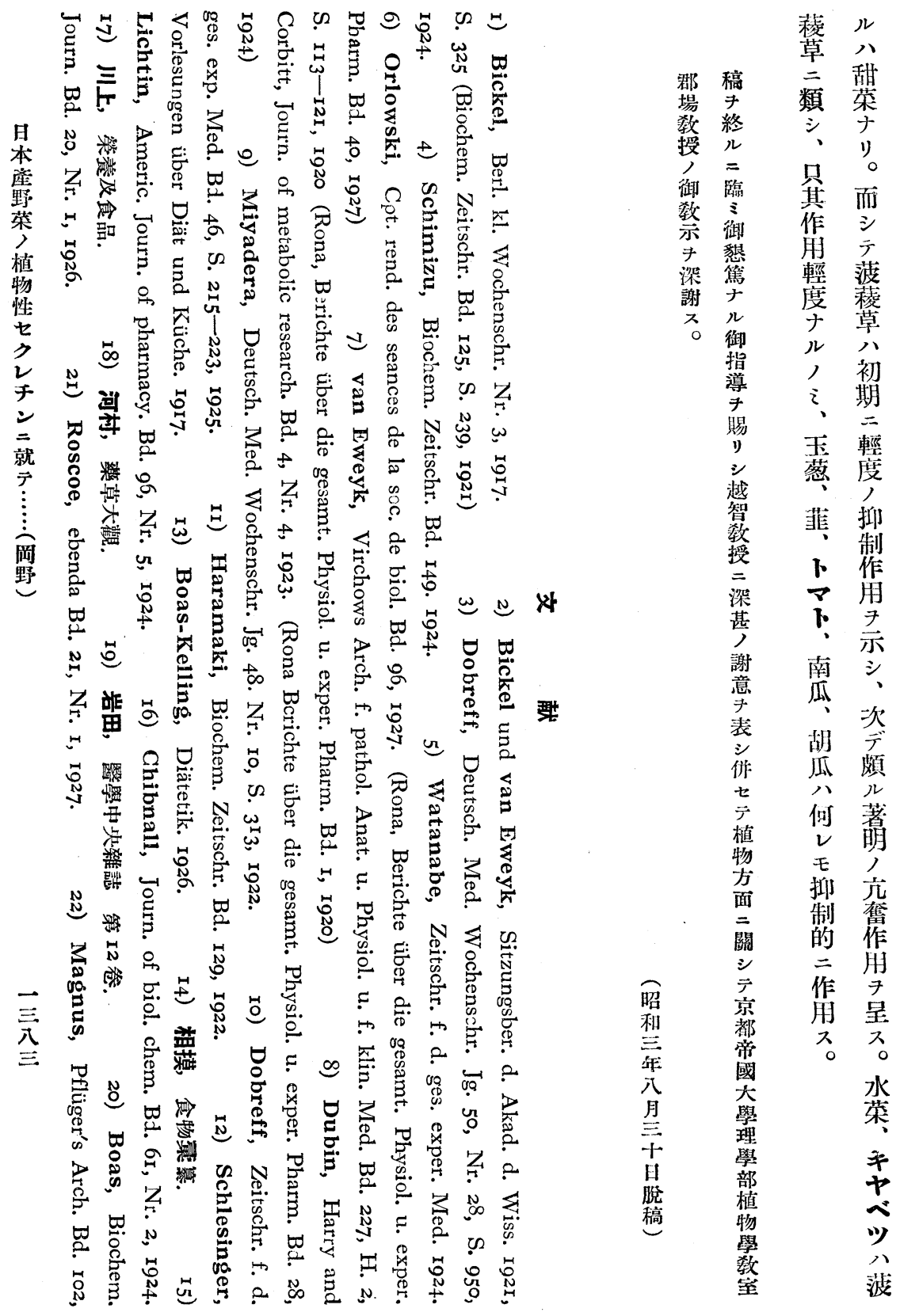
串 总象总

䒠范

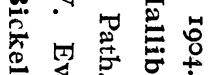

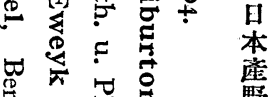

嵒

준

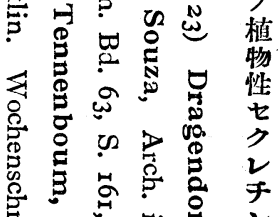

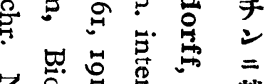

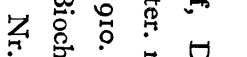

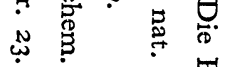

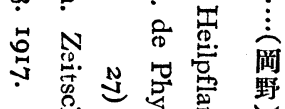

国总

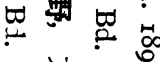

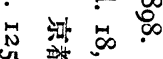

篦

范管

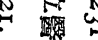

留

蛋等

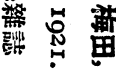

N

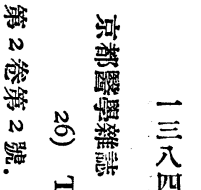

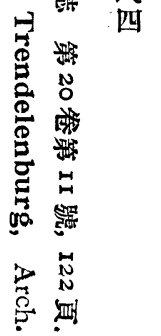


Die Resultate waren die folgenden:

Bei der Splenektomie nimmt die Leukocyten- und Erythrocytenzahl während eines Monats zu und dann bis zum Anfangswert wieder ab. Aber dabei bleibt der Haemoglobingehalt des Blutes einen Monat lang unverändert und zeigt sich darauf etwas vermindert. Bei der Entfernung der Milz u. Schilddrüse ist die Abnahme der Blutkörperchen die 1 Monat nach der Milzexstirpation auftritt, deutlich, während Hoemoglobingehalt und Färbeindex unverändert bleiben. Bei den milzlosen Tieren mit Schilddrüsenfütterung ist diese Abnahme gering und Haemoglobingehalt und. Färbeindex ohne Veränderung. Das Blutserum nach der Milzexstirpation weist fast immer Eiweissvermehrung auf, besonders Zunahme des Serumglobulins, während der Serumalbumingehalt fast stets unbeeinflusst bleibt oder höchstens eine geringe Abnahme zeigt. Die Serumviskosität geht mit dem Eiweissgehalt des Serums parallel. Diese Vermehrung des Eiweissgehaltes rührt wahrscheinlich von dem Fehlen des proteolytischen Ferments in Milz (wie H. Delanney et H. Serégé behaupten) her. Bei der Thyreo-splenektomie nimmt der Globulingehalt vorübergehend $\mathrm{ab}$ und dann wieder zu. Aber bei den milzlosen mit Schilddrüse gefütterten Tieren lässt sich keine Veränderung nachweisen.

Nach diesen Ergebnissen nimmt der Verfasser an, dass ein eiweissspaltendes Ferment in der Milz vorhanden ist und die Milz mit der Schilddrüse imstande ist, das Bluteiweiss zu regulieren und die haematopoetische Kraft des Knochenmarks zu beeinflussen. (Autoreferat.)

\section{UEBER DAS PFLANZENSEKRETIN IN JAPANISCHEM GEMÜSE. \\ Von}

Dr. T. Okano.

(Aus dem physiologischen Institut der medizinischen Akademie zu Kyoto. 
I) Im Salzsäureextrakte der japanischen Gemüse sind zwei Substanzen enthalten, von denen die erste auf die Bewegung des ueberlebenden Kaninchendarmes erregend, die zweite dagegen hemm. nd wirkt.

2) Jedes Gemüse enthält diese beiden Substanzen zugleich oder nur eine davon.

Die Menge dieser in den Gemüsen enthaltenen Substanzen ist je nach der Art des Gemüses sehr verschieden.

3) Diese beiden Substanzen sind im Wasser und absoluten Alkohol löslich, im Äther schwer löslich.

4) Bei der Substanz, die auf die Kontraktion des isolierten Kaninchendarmes erregend wirkt, handelt es sich um das sog. Pflanzensekretin von Bickel.

5) Die Substanz, die die Kontraktion des isolierten Kaninchendarmes hemmt, übt ferner auf den Blutdruck und die Atmung des Kaninchens und auf das isolierte Herz und die peripheren Gefässe der Kröte adrenalinähnliche Wirkungen aus.

Man kann also daraus entnehmen, dass diese hemmende Substanz dem Adrenalin sehr ähnliche Wirkungen aufweist.

6) Auf den isolierten Kaninchendarm wirken einige japanische Gemüse wie folgt:

a) Die Eierpflanze erregend,

b) Beta vulgaris, L. (Tautisa) total hemmend,

c) der Spinat zunächst leicht hemmend und danach deutlich erregend,

d) Midzuna und Kohl wirken wie Spinat, jedoch in viel geringerem Grade.

e) Zwiebel, Lauch, Tomate, Kürbis und Gurke hemmen alle.

(Autoreferat.) 